\title{
EL HOMBRE Y EL MEDIO EN SIERRA NEVADA (ANDALUCÍA) CRISIS Y CAMBIO
}

\author{
POR \\ JOAQUÍN BOSQUE MAUREL
}

Andalucía Oriental es esencialmente las Cordilleras Béticas, cuya porción occidental incluye. En Andalucía Oriental la provincia de Granada ocupa una posición central. Y en ella la existencia de las Cordilleras, con su centro neurálgico en Sierra Nevada, implica una considerable altitud media, superior al promedio andaluz e, incluso, al español. Es cierto que la Sierra, en sentido amplio, se alarga dentro de la provincia de Almería, hacia el extremo oriental andaluz, pero también lo es que casi toda la Sierra, y sobre todo su porción más significativa, forma parte de Granada. Erguida hasta casi los 3.500 metros, su relieve alomado y suave no da la impresión de gran altura, salvo por la presencia casi permanente de la nieve, hasta la que se escalonan casi todos los pisos bioclimáticos posibles desde el Ecuador. A manera de una gran bóveda paralela y próxima al Mediterráneo, la erosión apenas ha mordido a la montaña que no ha tenido - ni tampoco tiene- una auténtica vida de montaña como ha existido - y existe- en los Alpes y en los Pirineos. Se trata de una cordillera de campesinos, campesinos de reciente ocupación y raigambre tradicional que recuerdan la Meseta, pese a sus topónimos extraños, latinos romanceados muchas veces, $\mathrm{y}$ arábigos a menudo, con sus tierras de pan llevar, sus irrigadas paratas y sus pastizales incapaces por lo general de otro ganado que el lanar. La tradición aún dominante, pero dedrid.

Estudios Geográfico

Tomo LX, n. ${ }^{\circ} 235$, abril-junio 1999 
cadente, se enfrenta hoy a nuevos modos de vida, a nuevas gentes, también extrañas a la montaña y que, quizás, puedan transformar a largo plazo esa montaña recoleta y aislada. Aunque, sobre todo, en la lucha entre lo viejo y lo nuevo, entre la conservación y la innovación, la declaración de Parque Natural/Nacional (1989) ha convertido a Sierra Nevada en un modelo de Naturaleza a conservar pero también en un Hogar a mantener de gentes diversas por su origen y por sus costumbres. Aceptando el Parque Nacional como espacio bien definido y delimitado, Sierra Nevada suma una extensión de $1.716 \mathrm{~km}^{2}$ (171.646 has), repartidos entre las provincias de Granada - 37 municipios y 119.009 has- y Almería - 25 municipios y 52.647 has - . El espacio resultante integra comarcas tan cargadas de historia como la Alpujarra Alta granadina y almeriense, el Alto Genil y el Marquesado del Zenete, entre otras.

\section{La cordillera más alta de la Península Ibérica}

Sierra Nevada es la alineación montañosa más elevada de la Península Ibérica y una de las más altas de Europa. Sus picachos rebasan a los Pirineos en conjunto y en detalle: el Mulhacén tiene 3.481 metros; el Veleta, 3.392; mientras, la principal cima pirenáica, el Aneto, sólo asciende a 3.404. Y en Sierra Nevada, su línea de cumbres todavía ofrece otras por encima de los 3.000 metros: Alcazaba (3.366 m), Cerro de los Machos (3.327 m), Puntal de la Caldera (3.226 m), Tajos Altos y Cerro Pelado (3.144 m), Fraile de Capileira (3.201 m), Horcajo de Trevélez (3.182 m), Pico del Cuervo (3.150 m), Vacares (3.149 m), Buitrera (3.138 m), Tajos Negros (3.119 m), Picón de Jeres (3.086 m), Tajo de los Machos (3.081 m), Puntal del Goterón (3.075 m) y Cerro del Caballo (3.015 m). Resulta así esa característica silueta casi horizontal que sirve a la Vega del Genil de maravilloso telón de fondo y de espléndido dosel a la ciudad de Granada. La situación es casi idéntica respecto al conjunto de Europa; sólo los Alpes presentan un conjunto de gigantes capaces de superar a los penibéticos. Fuera de ellos únicamente el Etna, en Sicilia, y el CharDagh, en Yugoeslavia, superan los 3.000 metros.

Para algunos, precisamente la existencia de estas erguidas cordilleras explican esa afirmación tan repetida de que España es el país europeo de mayor altura media, después de Suiza. La realidad es muy diferente; los 640 metros de altura media de la península, el doble del promedio eu- 


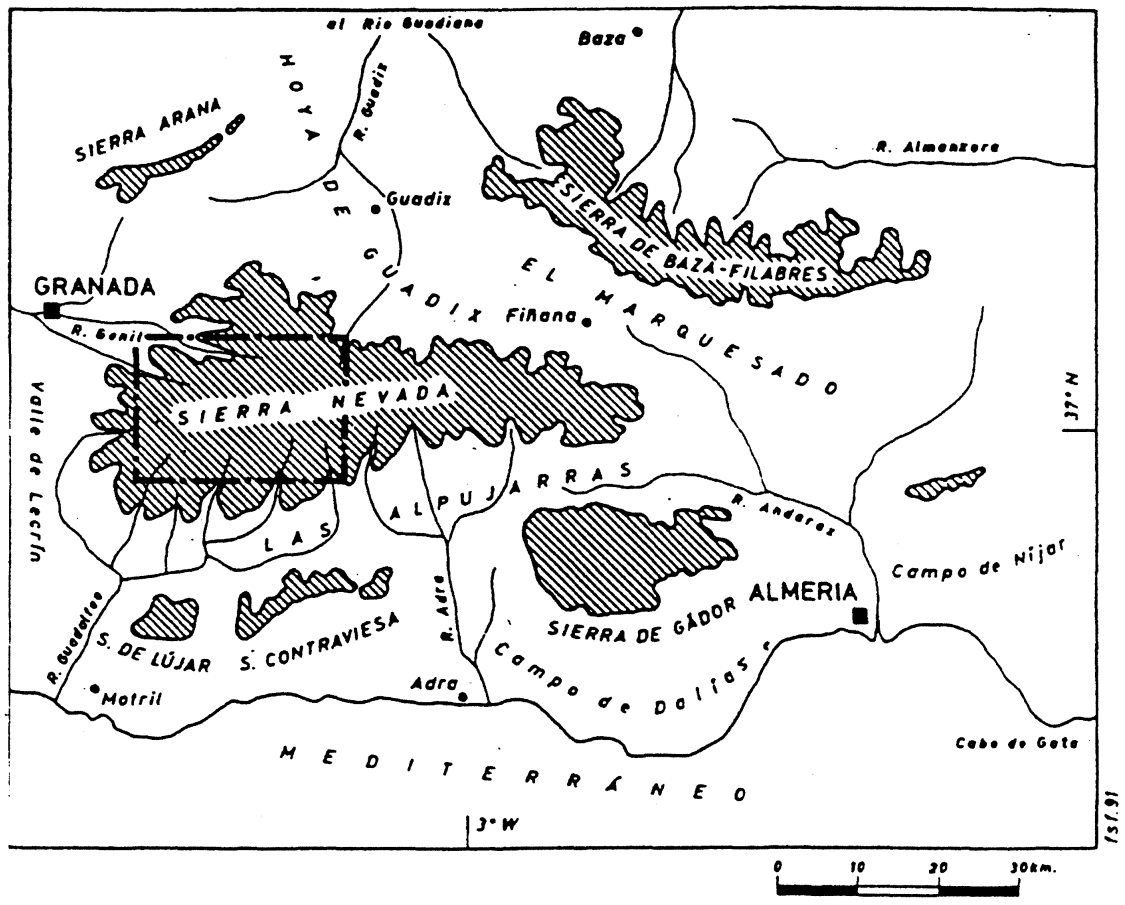

Fig. 1.-Situación de Sierra Nevada y las Cordilleras Béticas centrales.

ropeo (250 m), no resulta de la existencia de Sierra Nevada y de los Pirineos. Éstas son, ciertamente, una excepción ya que, en la Península, las tierras altas, por encima de los 2.000 metros, apenas significan el 1\% de la superficie total. En cambio, las antiplanicies y las mesetas, entre 200 y 800 metros, y las montañas medias, entre 800 y 2.000 metros, son muy abundantes, motivando esa elevada altura y, sobre todo, la trascendencia física y humana de la Meseta. Y, precisamente, ése es también el caso de la provincia de Granada; en ella, la alta montaña apenas implica el $2,84 \%$, mientras las tierras entre 800 y 1.200 metros abarcan el 50,5\% (Huguet del Villar, 1921, y Bosque Maurel, J., 1971).

Así pues, Sierra Nevada es, a la vez, una montaña alta, la más alta de la Península y una de las más elevadas de Europa, y una excepción en la geografía física hispánica y granadina. Su mismo nombre encierra una contradicción; una sierra en español es siempre una alineación mon- 
tañosa de no mucha altura, pero, en cambio, la nieve implica ya una altitud considerable y anormal - de aquí su denominación- en la posición astronómica de la región donde se encuentra, a orillas del Mediterráneo y muy cerca del paralelo $37^{\circ}$. Y su silueta, vista por cualquier viajero y, en especial, si está acostumbrado a la aspereza cambiante de los Alpes y los Pirineos, no traduce con claridad su altura aunque la presencia casi constante de la nieve constituye un matiz aparentemente altitudinal.

En el interior de la sierra la perplejidad aumenta, ya que el análisis de la vida serrana hace resaltar, en primer término, la carencia de una vida típica de montaña, al menos de vida similar a la de las grandes cordilleras de Centroeuroipa e, incluso, de otras más bajas del Norte de España, Pirineos o Montes Cantábricos. Los habitantes de la Sierra, de toda la Sierra, aun de aquellas porciones que se encuentran por encima de los 2.000 metros y que sólo se han habitado —se habitan - temporalmente, en verano, se esfuerzan en vivir y trabajar lo mismo que en las llanuras $\mathrm{y}$ mesetas que rodean la montaña y de las que frecuentemente proceden. En parte, señala Sermet, esta contradicción del hombre con la naturaleza se debe a la evolución histórica. Pero puede relacionarse también -posiblemente ésta es la razón fundamental - con la misma morfología, llegándose así «al hecho paradójio de que Sierra Nevada, montaña por su relieve, no lo es por su vida y esto a causa del mismo relieve» (Sermet, 1942).

Morfológicamente, Sierra Nevada es, en líneas generales, una montaña estructural poco afectada por la erosión cuaternaria y actual. Y, sin embargo, su relieve en relación con las depresiones que la rodean es imponente. Entre los 3.392 metros del Veleta y los 680 de Granada, en su borde noroeste, hay 34 kilómetros de carretera y menos de 20 en línea recta. Así, Sierra Nevada forma como una gigantesca cúpula alargada, compacta, elevada y carente de valles en esencia de origen fluvial que cuando existen son estrechísimos, de gran pendiente y sólo merecen el nombre de «barrancos», como los llaman los naturales del país. A diferencia de los Alpes y los Pirineos, profundamente disecados en macizos agrestes separados por valles profundos en artesa y muy individualizados, la Sierra es una unidad compacta sin apenas formas huecas y con un predominio absoluto de formas convexas muy suaves, que hacen aparecer las «lomas» e, incluso, los «llanos» — según la toponimia popularmuy cerca de las cumbres. Éste es el caso del «relieve» que contornea

$$
-210-
$$




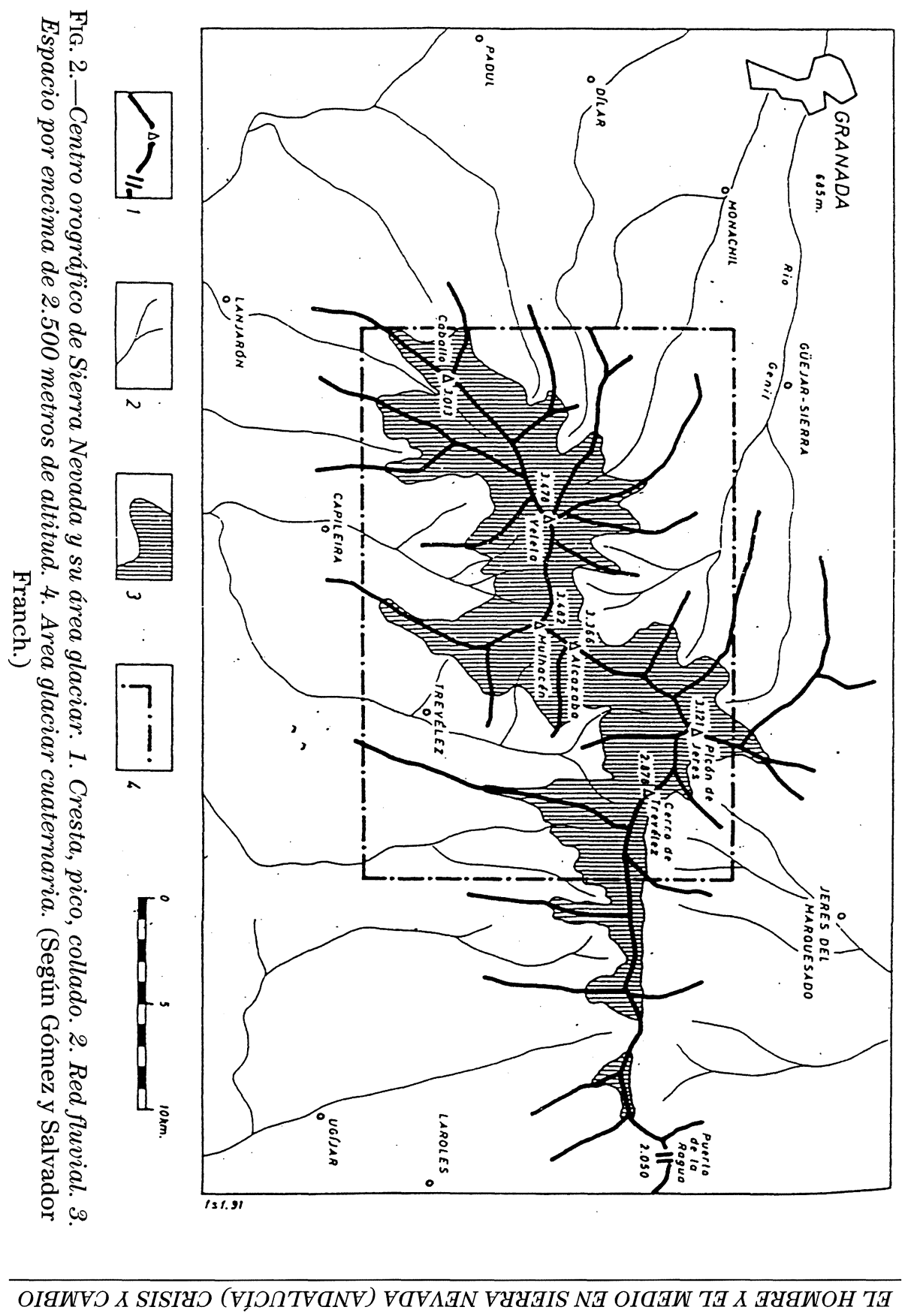


entre los 2.000 y los 3.000 metros, con sus formas redondeadas, pesadas y poco acusadas, el «corral» del Veleta. La juventud temporal de este relieve, el más reciente de la Península, así como la reducida importancia del glaciarismo cuaternario que apenas ha mordido en las cumbres, lo reciente y limitado de la erosión fluvial, la disposición y clase del roquedo - pizarras, calizas y conglomerados- en escamas superpuestas e inclinadas en el sentido de la pendiente, son las causas esenciales de esta peculiar morfología (Messerli, 1965, y Gómez Ortiz, 1996).

\section{Una montaña escasamente habitada}

Estas características del relieve han tenido sin duda alguna trascendencia en la vida humana de la Sierra. Sin valles que faciliten la penetración, el poblamiento ha sido siempre escaso y está limitado a determinadas partes. Pero, también, su altura uniforme y constante ha dificultado las relaciones entre sus diferentes vertientes, a cada lado de la línea de cumbres. Asimismo, en algunas ocasiones, esta misma resistencia a la ocupación por el hombre ha motivado su conversión en un refugio frente a ciertos peligros, a determinadas invasiones. Finalmente, este relieve poco humanizado, en unión al clima, ha podido facilitar unos modos de vida que en poco recuerdan a los de otras montañas que tienen menos altura que la Sierra.

En primer lugar, nos encontramos ante una montaña escasamente habitada, aunque desde muy antiguo, ya que existen restos arqueológicos que se remontan, al menos, al Neolítico. En efecto, Sierra Nevada, considerando como tal el espacio administrativo incluido en el Parque Nacional —62 municipios-, tiene, actualmente, según el censo de 1991, 82.953 habitantes - 64.921 pertenecientes a la provincia de Granada y 18.035 a la de Almería - y una densidad de población muy baja, inferior a los 25 habitantes por kilómetro cuadrado. En realidad, como casi todos estos municipios tienen una parte considerable de su territorio en las regiones periféricas más llanas y son estas partes las que fijan esencialmente las actividades humanas, y por tanto, las más de las gentes de dicha población relativa, aún será menor en las áreas más elevadas, a menudo - al menos temporalmente- completamente deshabitadas. Sólo muy recientemente, el turismo de nieve ha provocado alguna ocupación importante y densa en altura, por encima de los 2.000 metros. 

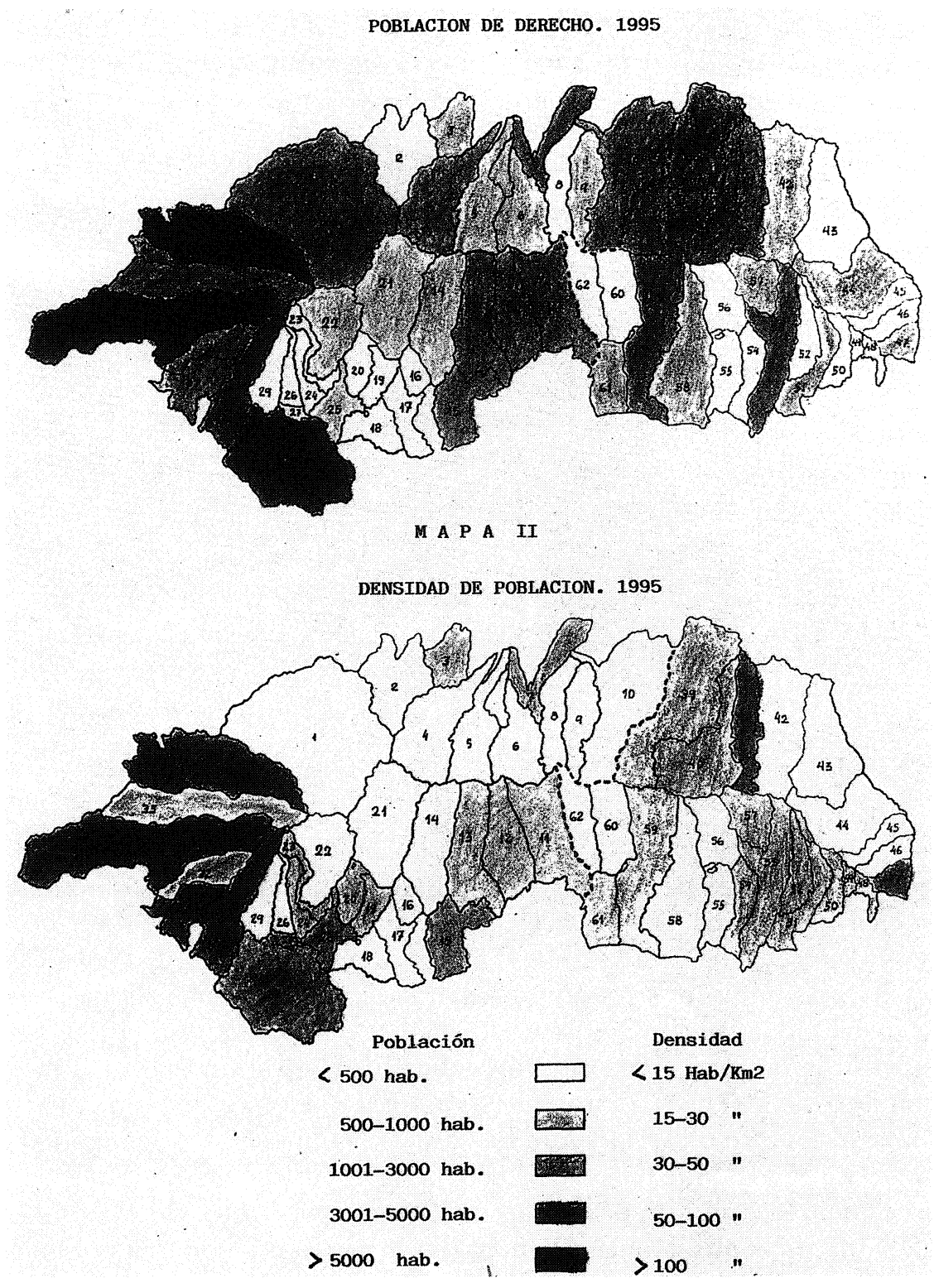

Fig. 3.-Población de derecho y densidad de población en 1995. (Según Cózar Valero y Arias Abellán.) 
Si de los 62 municipios que forman parte del Parque, se descontasen los correspondientes a su borde sudoccidental y que, tradicionalmente, han formado parte de la Vega de Granada y del Valle de Lecrín -Dúrcal, Gójar, Lanjarón, Lecrín, Nigüelas, Padul y La Zubia—, la población serrana se limitaría a 48.881 almas. Incluso si nos atuviésemos a los habitantes existentes dentro de los límites estrictos del Parque su número descendería hasta solo 18.642 serranos $-22,5 \%$ de toda Sierra Nevada-, 11.387 almerienses y 7.255 granadinos, con una densidad muy reducida, apenas cinco habitantes por unidad kilométrica (Rodríguez Martínez, F., y Arias Abellán, J., 1996).

Además, Sierra Nevada eleva su hábitat a una altitud mucho más baja que otras cordilleras españolas situadas a latitud más nórdica, y por consiguiente, afectadas por un mayor rigor climático. En conjunto, el hábitat de Sierra Nevada no ha rebasado nunca los 1.500 metros de altura, al menos de una forma permanente. Trevélez, tradicionalmente considerado como el lugar habitado más alto de la Península Ibérica, se encuentra a sólo 1.476 metros, a una altitud, por tanto, más baja que la de algunos núcleos del Pirineo central, como Tor, en el Pallars, que se alza a 1.710 metros, nivel equivalente o ligeramente inferior a la de otros lugares de la Sierra de Gredos y menor, asimismo, a la que adquiere el hábitat permanente en la Sierra de Albarracín, como Griegos, a 1.602 metros (Floristán, A., y Bosque, J., 1957, y Carvajal, 1986).

Esta población aparece muy mal distribuida, en número y altitud, según las vertientes. En la umbría, en la la ladera septentrional recorrida por los altos valles del Genil y el Guadiana Menor, los núcleos no llegan nunca a rebasar los 1.300 metros, como ocurre con Aldeire $(1.277 \mathrm{~m})$, el pueblo más alto de esta vertiente, superior a Güejar-Sierra, a sólo 1.084 metros; en conjunto, sus habitantes, unos 22.659, apenas significan un tercio del total, distribuidos en agrupaciones compactas entre 500 y 1.000 almas situadas casi todas ellas en el borde inferior del Parque. Por encima de los 1.300 metros, aparece el hábitat disperso - cortijadas, cortijillos-siempre o casi siempre de carácter temporal, sólo ocupados en verano y que asciende hasta los 1.800 metros ocasionalmente. Aparte hay que considerar el complejo turístico, muy moderno, de Pradollano ( $2.200 \mathrm{~m})$, en el alto Monachil, un afluente del Genil, con una población permanente de alrededor de 4.218 personas en 1991, pero que en plena temporada turística invernal puede albergar a unas 10.000 almas e, incluso, un número mayor. 
La solana, la Alpujarra Alta, tanto almeriense como granadina, más el Andarax medio y su espacio occidental, sobre la Vega granadina y el Valle de Lecrín, la más poblada, reúne alrededor de los dos tercios de los habitantes de la Sierra, casi 57.000, distribuidos en un mayor número de núcleos de población que en la umbría, y de dos tipos diferentes, los que oscilan entre 1.000 y 5.000 habitantes, los menos, y los que tienen alrededor de 500 almas. Los pueblos de la Alpujarra suben más que los del Alto Genil y el Marquesado, llegando hasta cerca de los 1.500 metros, como Trevélez, el núcleo permanente de población más alto de la Sierra, a 1.476 metros en su barrio más alto. Después, a más altura, aparece el hábitat temporal, disperso en «cortijillos», que se aproxima difícilmente - se aproximó más bien- a los 2.500 metros.

En ambas vertientes, sólo rebasan estos respectivos límites superiores $-1.250 \mathrm{~m}$ en la umbría y 1.500 en la solana- algunos pocos refugios de alta montaña, construidos con fines deportivos; los existentes a mayor altura son los Albergues de alta montaña de Río Seco y Elorrieta, próximos al Veleta, a más de 3.000 metros, y el albergue forestal de Lanjarón, a casi 3.000 metros de altitud (Bueno Porcel, 1987).

Detenido el hábitat permanente a los 1.500 metros como máximo, los contactos entre las dos vertientes de Sierra Nevada han sido - y son todavía - limitados y escasos dada la presencia de una línea de cumbres contiguas que rebasa, al menos, los 2.500 metros a lo largo de una longitud de unos 80 kilómetros entre el Cerro del Caballo al Oeste, con 3.015 metros, y el Cerro del Chulo, al Este, con 2.606 metros, y apenas si presenta, lateralmente, algún puerto que, como el de la Ragua, a oriente, supera ligeramente los 2.000 metros, y el del Veleta, próximo a los 3.000, en el centro, no son fácilmente accesibles durante los meses de invierno. Así hasta hace muy poco tiempo no ha sido posible la apertura de una pista de montaña que atraviese de un lado a otro el macizo central, si bien existe, desde 1936 una bien trazada carretera hasta la cumbre del Veleta, que es considerada, tradicionalmente, como el acceso carretero más alto de Europa (Titos, 1993). En realidad, aparte las rutas periféricas, el único acceso abierto todo el año al tráfico, aunque con grandes problemas en invierno, y que enlaza las dos vertientes, se encuentra en la mitad oriental de la Sierra, de altitud inferior a la parte occidental y que utiliza el Puerto ya citado de la Ragua, por otra parte muy próximo al conjunto central de cimas más altas. 


\section{Una barrera y un refugio}

Por ello, en todos los tiempos, el aislamiento en que han vivido las gentes de la Sierra ha sido considerable y, sobre todo, la desconexión entre las dos porciones esenciales del país granadino, la Costa y las Depresiones interiores de Granada y Guadix, muy grande. Las relaciones principales entre ambas se realizan todavía bordeando lateralmente, por el occidental valle de Lecrín y Lanjarón, o por el oriental río del Andarax, el macizo serrano o, en todo caso, en verano, aprovechando las mayores facilidades - menor altura, con numerosos pasos transversales por debajo de los 2.000 metros - ofrecidas por la mitad oriental de la Sierra.

Así se explica que, si bien el contacto Motril-Granada, a través del Valle de Lecrín, uno de los rincones más encantadores del antiguo Reino de Granada, es fácil relativamente y muy antiguo, los pueblos alpujarreños busquen su expansión primero en la Costa y, luego, más allá de los mares, en el Norte de África y en Sudamérica, receptores de una añeja emigración, mejor que en las altiplanicies del interior. Incluso, históricamente, cuando salvaban la divisoria, su meta fue $-\mathrm{y}$ en cierta forma sigue siendo -más bien Guadix - convertida así en uno de los principales mercados de la Alpujarra (Brenan, 1957) que Granada, más próxima físicamente pero más lejana por la interposición de la muralla serrana que obliga al enorme rodeo del río de Ugíjar o el Valle de Lecrín. Esta realidad explica muchos de los acontecimientos militares de la rebelión de los moriscos y, sobre todo, el papel desempeñado en esta lucha por Padul y el puente de Tablete, ingresos principales desde la Vega o desde la Alpujarra en el Valle de Lecrín, pero emplazados fuera de la Sierra, en su borde occidental, al norte y al sur respectivamente del Valle.

Auténtica barrera, Sierra Nevada ha sido muchas veces un codiciado refugio. Si observamos, aunque sea superficialmente, cualquier mapa de España, resalta enseguida la existencia de una inmensa masa montañosa denominada por los geógrafos con el nombre de Cordilleras Béticas, que se extiende sobre más de 500 kilómetros de longitud desde Gibraltar hasta el cabo de la Nao. Este poderoso conjunto orográfico, el mayor de la Península, está formado por dos alineaciones fundamentales paralelas entre sí y llamadas por Solé Sabarís (1952), la costera, Cordillera Penibética, y la interior, Sistema Subético. Entre ambas se encuentra un rosario de depresiones, el Surco Intrabético, que dice Sermet (1953), o Pe- 
nibético, según Solé, y que constituye la más importante línea de comunicación interna del Sudeste peninsular entre el Mediterráneo Occidental y el golfo de Cádiz. El conjunto aparece a nuestra vista como una gigantesca fortaleza natural que tuviese su plaza de armas en la más central de las hoyas interiores del Surco, la depresión de Granada, y su Torre del Homenaje en Sierra Nevada. Su utilización como tal fortaleza era lógica y ha sido una constante histórica en el devenir de los pueblos que han habitados esas regiones.

Tres momentos han sido esenciales en esa función de refugio. El primero en el tiempo tuvo lugar en los primeros siglos de la invasión musulmana, cuando el conjunto de la Penibética fue el núcleo de la resistencia españolista (?) —mozárabes y muladíes coaligados- frente a la dominación extranjera representada por los Omeyas del Emirato de Córdoba. Así, Omar ibn Hafsun, caudillo hispánico, contó siempre con la ayuda de los habitantes de la «cora» de Elvira que tuvieron por capital a Granada, y por núcleo mayor de resistencia el mediodía de Sierra Nevada, la Alpujarra central, con su núcleo de máximo apoyo en el castillo de Juviles (Sánchez Martínez, 1980, y Trillo San José, 1996).

Mayor repercusión tuvo el segundo momento, al organizarse en el siglo XIII el último reducto musulmán en España, el Reino de Granada. En principio, la coincidencia entre éste y las Cordilleras Béticas fue casi absoluta; precisamente, su aislamiento tras la muralla montañosa, su posición central en el camino de ronda del rosario de depresiones interiores y el sentirse protegido y respaldado por Sierra Nevada, fueron razones básicas en el predominio de la ciudad de Granada y de su promoción al primer lugar entre las ciudades españolas de finales del siglo xv (Bosque Maurel, 1962).

Más tarde, en un tercer momento, caído ya el reino nazarí, en Sierra Nevada, en su vertiente meridional, en la Alpujarra más exactamente, con motivo de la guerra de los moriscos (Hurtado de Mendoza, 1970), estuvo el postrer foco de resistencia del Islam español ante la expansión cristiana; como en el primer momento de la ocupación muslín, en Juviles tuvo lugar una de sus últimas batallas. Y, así, la Alpujarra, uno de los postreros refugios de la Cruz ante los musulmanes, lo fue también de éstos frente a la Cristiandad. Y aún cabría referirse a la resistencia ofrecida por los montañeses de la Sierra a las huestes de Napoleón; los ejemplos, ya legendarios, durante la guerra de Independencia, de Lapeza, en len-

$$
-217-
$$


gua de Alarcón, y del alcalde de Otívar, el más famoso guerrillero de una región que abundó en ellos, son bien conocidos.

\section{Una cordillera de campesinos}

El hábitat de la montaña más alta de la Península, de este gran refugio natural, ha estado sostenido casi exclusivamente $-\mathrm{y}$ hasta no hace mucho tiempo- por unos modos de vida apenas ligados con las características actividades de las regiones montañosas y, sobre todo, con la vida de alta montaña del Centro de Europa. Si los municipios pirenáicos (Solé Sabarís, 1951) y los núcleos de población de los Alpes (Veyret, 1972) dependen esencialmente de los propios recursos de la montaña, los pueblos de Sierra Nevada han estado - y aún están-, en buena parte, ligados con las regiones periféricas, por las que frecuentemente se extienden sus superficies administrativas y en las que, muchas veces, se encuentran sus principales entidades de población. Éste es el caso, por ejemplo, de los pueblos del Zenete que, si bien se extienden hasta la línea de cumbres viven ante todo en y de la altiplanicie existente a su pie (Carandell, 1936, y Arias Abellán, 1984). En conjunto, Sierra Nevada es una cordillera de campesinos, en la que tiene escasa importancia la ganadería y no existe ninguna de las actividades que se encuentran tan profusamente en las cordilleras centroeuropeas, las pequeñas industrias artesanas de la madera y el hierro, por ejemplo. Incluso, muchas modernas actividades de la montaña, tan difundidas en los Pirineos y en los Alpes, como los deportes de la nieve o la explotación hidroeléctrica, sólo en fecha muy tardía han penetrado en Sierra Nevada.

La agricultura ha sido - y es-, por tanto, el modo de vida principal de la Sierra: todavía en 1981 la población ocupada por las actividades agrarias significaban el $68,1 \%$ del total. Y, precisamente, una agricultura muy parecida a la de las tierras periféricas. Esto es, al menos, válido hasta cierta altura, la del límite superior de los cultivos, ya que no deja de existir una cierta gradación altitudinal, lógica en una cordillera que, desde las cálidas aguas del Mediterráneo, se alza hasta cerca de los 3.500 metros, donde domina la «tundra» o las nieves eternas. Por ello, como cordillera eminentemente mediterránea, es la agricultura propia de los países ribereños del «Mare Nostrum» la predominante en el conjunto de 


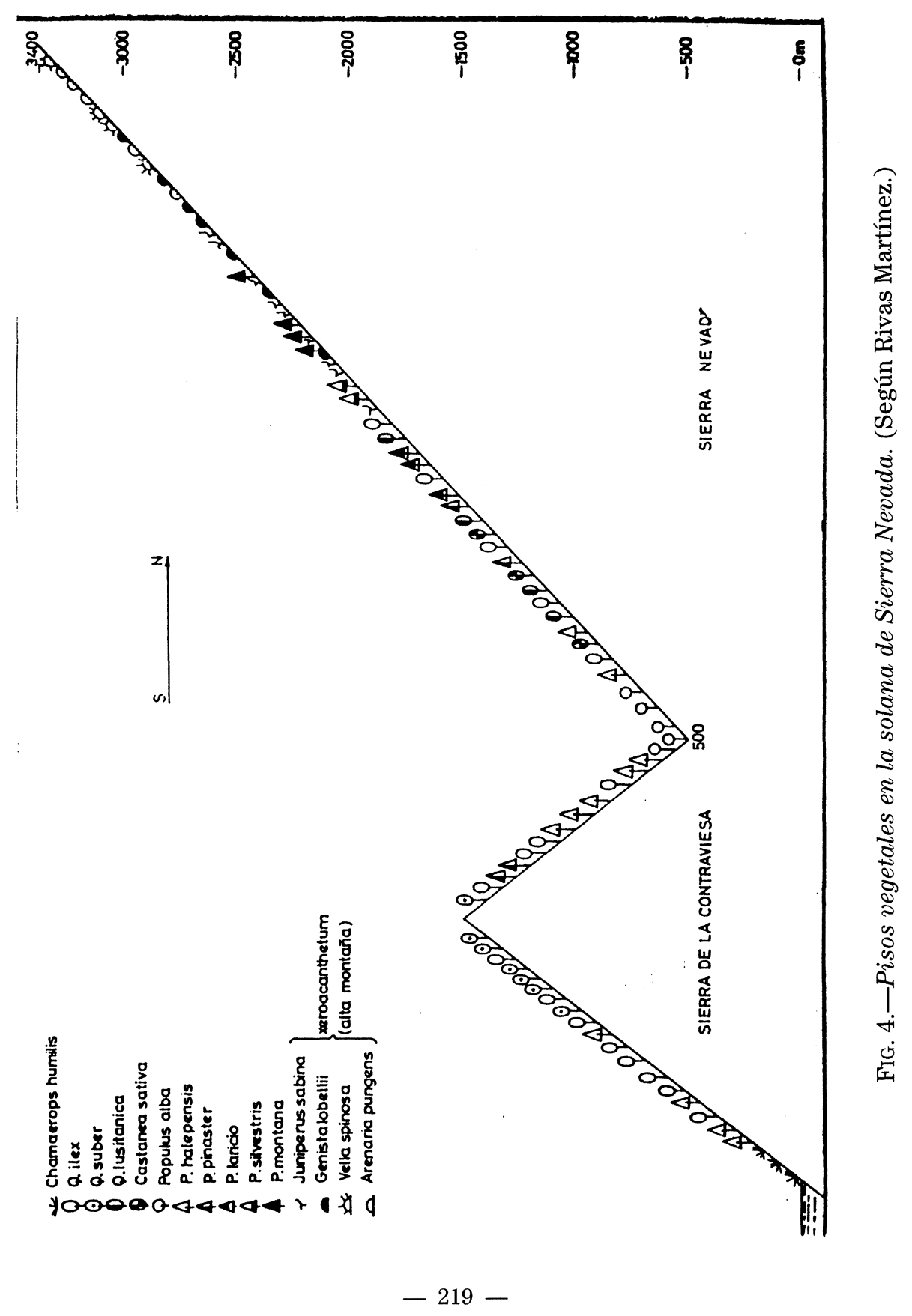


Sierra Nevada. Sin embargo, es interesante observar cómo los cultivos mediterráneos típicos, pese a la latitud próxima al Trópico, sólo alcanzan una altura relativamente baja, unos 1.100 metros en la umbría y 1.400 metros en la solana, hasta donde llegan, más o menos mezclados, casi siempre en regadío - un sistema de utilización del suelo fundamental al menos desde el medioevo-, cereales de invierno, viñedos, olivos, nogales y castaños. Después, hasta los 1.300 y 1.800 metros respectivamente, ascienden, con el castaño y, a veces, la encina y el quejigo, las tierras de pan llevar, unas veces en secano y otras en regadío, con trigo y cebada en invierno, y maíz, habichuelas y patatas en verano. Incluso, en los valles protegidos y soleados, aparecen algunos de los frutales propios de latitudes más altas, castaños, cerezos, manzanos, nogales y avellanos, siempre asociados con los cultivos estrictamente mediterráneos.

En este piso vegetal y agrario, la orientación desempeña un importante papel; mientras que en el Valle del Genil, en la umbría, abundan castañares y robledales, en la Alpujarra, en la solana, son más escasos, formando únicamente isleos dispersos intercalados con viñedos, almendros, higueras e, incluso, en los niveles inferiores moreras y naranjos. Por todo ello, se ha podido afirmar (Carandell, 1994) que «mientras los labradores de Güejar y Monachil almacenan bellotas y cerezas, (los alpujarreños) guardan almendras y naranjas (y que mientras) aquellos conservan patatas bajo la nieve, éstos secan higos al sol». Pero, sobre todo, a partir de los 1.300 metros en el norte y de los 1.500 en el mediodía, se entra ya en el ámbito de las praderas y de los cultivos temporales de verano - centeno, trigo, patatas - que asciende - ascendía más bien-, respectivamente, hasta los 2.000 y 2.400 metros. Finalmente, la región de seminieves permanentes, como la más elevada de nieves perpetuas, se acantona estrictamente en la divisoria de aguas y en el fondo de las hoyas glaciares que jalonan los picachos más elevados, Mulhacén, Alcazaba, Vacares, Veleta, y únicamente admite una ganadería temporal, sólo estival. Aparte los ya desaparecidos aprovechamientos de la nieve - los «neveros»- todavía presentes en los años treinta y abastecedores de las ciudades de su entorno, Granada, Guadix, Motril, y que provocaron el «camino de los neveros», uno de los accesos principales a las más altas cumbres serranas, seguido por Willkoan (1997) y Nicolás María López y la Sociedad Excursionista Diez Amigos Limited (1992), entre otros muchos. 
Ahora bien, por encima del piso estrictamente mediterráneo, ni los cultivos arborescentes son muy frondosos ni los pastizales muy extensos, jugosos y frescos. En cambio, son frecuentes las laderas desnudas, apenas cubiertas por un matorral leñoso muy disperso, donde resalta el gris plata de las calizas dolomíticas o el negro acerado de las pizarras cristalinas. $\mathrm{Y}$ en todos los pisos, cuando los campos o los pastos verdean y relucen al sol, es porque la montaña está recorrida por las acequias, posiblemente morunas y, al menos, medievales que recogen y distribuyen el agua procedente de los barrancos alimentados por los neveros, antiguos glaciares. La latitud, y más aún la proximidad de los anticiclones tropicales, limita la extensión de las zonas agrarias. Si, en invierno, el frío intenso y la innivación dificultan los cultivos, en verano, la sequedad se hace muy intensa, agravándose con las altas temperaturas que provocan una fuerte evaporación. Así, el uso del regadío es casi obligado y, a menudo, imprescindible y existe por todas partes, hasta el nivel donde es ya difícil el aprovechamiento agrario. Y, siempre, el predominante pequeño campesino, bien sea propietario o, más corrientemente, colono, realiza una labor absorbente e intensa, casi de estricta jardinería, y que exige, como tarea previa, la construcción de los característicos bancales (paratas) que escalonan las pendientes y abundan, sobre todo, en la vertiente meridional, y en la que no faltan las tareas conjuntas y en colaboración entre las distintas unidades familiares, el «tornapeón», según el lenguaje popular (Bosque Maurel, J., 1979).

La minuciosidad de las labores agrícolas se complica en el estío, al menos hasta finales de los años setenta, con la aparición de los cultivos temporales, ligados íntimamente a una ganadería marginal. El pastoreo, género de vida tan típicamente de montaña, se encuentra - siempre se encontró- en Sierra nevada poco desarrollado, a causa sobre todo de la sequedad estival. Por ello, el ganado es escaso y casi exclusivamente menor. Si el porcino permanece estabulado y el vacuno, que aparece sólo en algunos municipios de la Alpujarra Alta, asciende, sin salir de los límites administrativos, a los pastos estivales de altura, el ganado lanar, con el cabrío, realiza una característica trashumancia entre la Costa y la Sierra, hoy casi desaparecida por la extensión de un regadío muy reciente en los Llanos litorales de Dalías y Carchuna, por ejemplo. La permanencia en la Sierra es más prolongada de lo acostumbrado en la montaña mediterránea, iniciándose la subida en mayo y descendiendo a fines de octubre. Así era al menos hasta poco antes de los años cin- 
cuenta, como atestiguan muchos de los viajeros llegados a Granada en sus relatos y descripciones (Boissier, 1995, y Willkomm, 1993), aunque no han desaparecido del todo estos viejos modos ganaderos.

Los rebaños, primero, se reunían en torno a los pueblos más altos desde donde, cuando llegaba junio, se dirigían al área de hábitat temporal situado a partir de los 1.500 metros en unión de numerosas familias de cultivadore estivales que se detenían en los «cortijillos» con sus animales de labor. Aquí abrían los «silos» que, bajo la nieve del invierno, habían conservado las semillas y se labraban y sembraban los campos que permanecían cultivado desde mayo a octubre, y acaso noviembre, y daban cosechas de centeno y patatas. Los rebaños, por su parte, rebasaban - y rebasan - el piso agrícola temporal que alcanzaba su máximo hasta los 2.800 metros en la ladera sur, siguiendo a la nieve en retirada a fin de refugiarse enseguida en las cumbres, donde sólo las hoyas detrás de las morrenas glaciares cuaternarias, que conservan más la nieve, son más húmedas y de hierba más jugosa y fresca, los «borreguiles» según el habla de los montañeses.

En septiembre, los agricultores nómadas y los rebaños trashumantes iniciaban - hoy solo el ganado- juntos el descenso hasta los primeros núcleos permanentes, donde el ganado descansa cerca de un mes a fin de estercolar los campos destinados a recibir los cereales de invierno. Después, en noviembre, ovejas y cabras descendían — desciendenhasta los llanos litorales para invernar; desde allí, a fines del mes de abril, comenzarán el retorno. A estos desplazamientos agrícolas y pastoriles se superponía - muy reducida y en decadencia-, en pleno verano, una tercera ola formada por los recolectores de manzanilla y otras plantas medicinales y aromáticas que, por encima de donde pastan los rebaños, subían hasta las crestas (Sorre, 1931). Una última oleada últimamente muy mermada por la declaración de especie protegida, y por tanto no cosechable legalmente, de la manzanilla serrana (Artemisia granatensis), uno de los diversos endemismos serranos reservados y defendidos por la legislación vigente.

Tampoco el bosque, como la ganadería, ofrece muchas posibilidades, siendo muy escasas las grandes formaciones forestales, que no rebasan apenas los 2.200 metros. Es tradición que toda la Sierra estuvo cubierta de pinos (Pinus nigra y sylvestris), pinsapos (Abies pinsapo), castaños (Castanea sativa) y quejigos-melojos (Quercus pyrenaica); así parece deducirse de los escritos de los geógrafos medievales y, sobre todo, de 
algunos botánicos que, como Boissier (1995) y Willkomm (1993 y 1997), recorrieron estas alturas durante el siglo pasado. Existen todavía algunos parajes bien arbolados en Güejar Sierra y el valle del Maitena, en la umbría, así como, en menor extensión, en los altos valles de los «barrancos» meridionales de Lanjarón, Poqueira y Bérchules. Y a ellos cabe añadir las importantes manchas de pino carrasco (Pinus halepensis) y encinares (Quercus rotundifolia) y/o alcornocales (Quercus suber) de la Alpujarra Baja, entre las que se destaca el espléndido alcornocal del Haza del Lino, en la sierra de la Contraviesa, que se levanta entre los 800 y los 1.300 metros, uno de los más altos y meridionales de la Península. Pero la construcción de los edificios granadinos, como la Alhambra, y las exigencias de la marina primero musulmana y después cristiana, habrían acabado con muchos de estos conjuntos forestales.

Actualmente, las actividades derivadas de la madera no existen, y pudiera pensarse que, acaso, nunca tuvieron alguna importancia. Las pizarras cristalinas de la bóveda central de Sierra Nevada, con sus bruscas alternativas térmicas periglaciares y su suelo frágil y esquelético, no parecen haber sido capaces nunca de sostener un bosque frondoso, como tampoco las resecas calizas triásicas de la orla exterior resultan muy asequibles a una vegetación abundosa. En todos los casos, el verano es demasiado árido y sólo en el fondo de los barrancos, a menudo muy estrechos, aparece una abundante vegetación ripícola, fresnos (Fraxinus angustifolia), álamos (Ulmus minor) y alisos (Salix atrocinerea). La desforestación ha activado la erosión del suelo que, en algunos puntos de la vertiente meridional tiene $o$, al menos, ha tenido consecuencias catastróficos que sólo está pudiendo moderar la repoblación, en muchos casos modélicas, pero que en otros apenas ha conseguido resultados limitados. En todo caso, a esta repoblación, iniciada a finales de los años cuarenta en relación con las grandes obras hidráulicas de los valles del Genil y del Guadiana Menor, hay que atribuir las más importantes masas arborescentes - por lo general pinares, carrasco, en el piedemonte, pinaster y silvestre en los niveles altos- que existen en la accualidad (Arias Abellán, 1981).

En íntima relación con la originalidad botánica se encuentra su peculiar fauna, en la que cabe destacar, a diferencia del Pirineo y otras cordilleras europeas, la escasez de especies propiamente nivales. Y, por consiguiente, la recolonización estival de la alta montaña por una fauna de origen mediterráneo y estepario llegada de los niveles inferiores. 


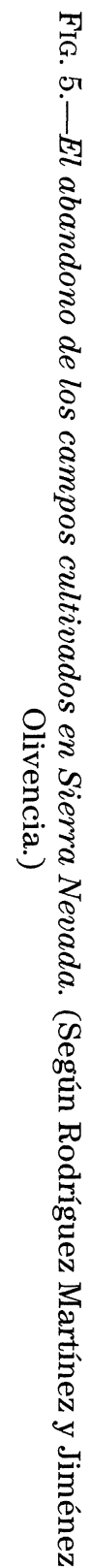

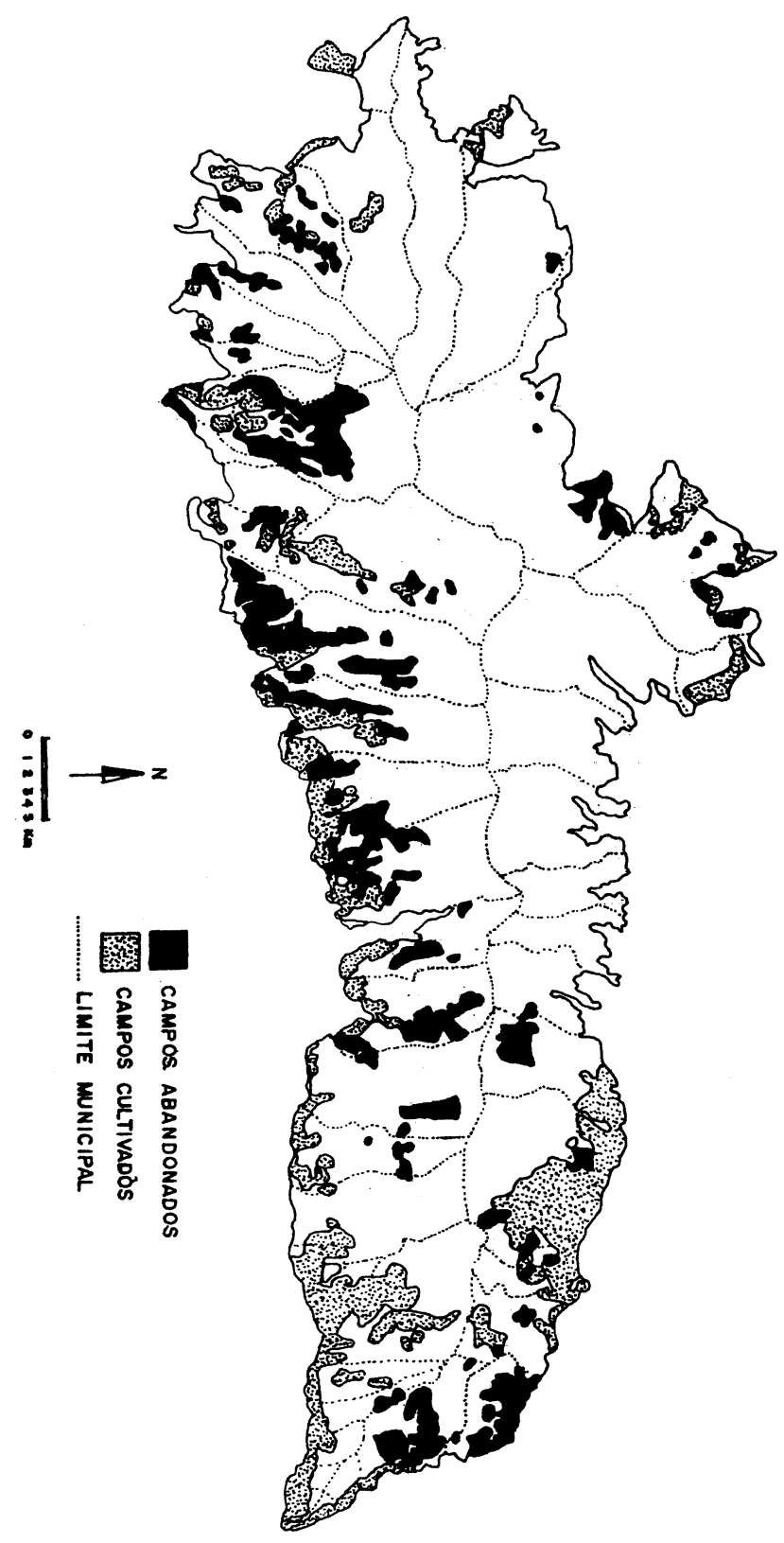

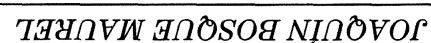


Sin tener en cuenta a los diversos y abundantes invertebrados, son varias las especies propias de la Sierra. Por ejemplo, aves, como la chova piquirroja, la tórtola común, el cuco o el pinzón vulgar, así como mamíferos, zorros, tejones y ginetas, de los que el primer lugar corresponde a la cabra montés (Capra pyrenaica), que por tradición se ha hecho emblemática en Sierra Nevada. Aunque en los años cincuenta y sesenta la cabra montés estuvo en peligro de extinción, actualmente, pese al furtivismo, su recuperación, ligada sin duda a la existencia de una «Reserva Nacional de Caza», es evidente y su número muy elevado, como su menor timidez y su más fácil contemplación (Rodríguez García, M., 1965).

La evolución reciente de la Sierra ha introducido importantes cambios en las actividades y en el modo de vida de sus gentes. Incluso se está hablando y, con razón, de crisis (Rodríguez Martínez, 1981), una crisis a la que, por otra parte, no son ajenas casi todas las regiones montañosas de la Tierra. Y, en concreto, del Mediterráneo (Isnard, H., 1973, y Bosque Maurel, 1982). En el caso de Sierra Nevada es indudable la crisis por la que están pasando sus modos de vida tradicionales, una crisis además muy reciente, relacionada con la falta de competitividad de la producción agrícola, la especulación urbanística y el impacto de un turismo rural mal planteado. Una resultado evidente de los cambios que están acaeciendo es la regresión, la decadencia, de las actividades agrarias en general y de las agrícolas en particular. Así, en el Censo de 1991, la población ocupada por el sector primario no llegaba al 30\% (28,8\%) del total (Rodríguez Martínez, F., y Arias Abellán, J., 1996).

Regresión demográfica percibida en primer lugar en el retroceso de los espacios cultivados en general. Un retroceso iniciado con la desaparición de los viejos modos de vida temporales y que, en la práctica, ha implicado el total abandono de las tierras cultivadas por encima de los 1.200/1.500 metros y, en menor medida, de los pastizales y de la ganadería cercanos a la línea de cumbres. Pero, también es sensible el paulatino abandono tanto de los bancales regados de antañona ocupación como de los «campos» de secano, del deterioro creciente del sistema de irrigación desarrollado desde la Edad Media y de la ocupación por una vegetación espontánea, retama, hiniesta, jara, del terruño abandonado. Todo ello, en muchos casos, está acompañado por la generalizada erosión del suelo y su consiguiente desertizado. Una nueva realidad que no está consiguiendo evitar la introducción todavía leve y en muy con- 
cretos lugares, como el Barranco de Poqueira, de una agricultura nueva, ecológica esencialmente y basada en principios mercológicos y con denominación de origen. Según los datos aportados por Rodríguez Martínez y Jiménez Olivencia (1994 y 1996) puede calcularse que en torno a un tercio de los terrenos agrarios de la Sierra, especialmente, en su vertiente y periferia meridional, han sido abandonados en los tres últimos decenios, con un impacto concreto y agresivo no sólo en el paisaje sino también en el poblamiento y el hábitat.

\section{Una vivienda peculiar y adaptada al medio}

En estos modos de vida serranos, la vivienda desempeña un papel esencial. Con la particularidad de que «si, por una parte responde a las líneas generales del hábitat del Mediterráneo, por otra intenta —y lo consigue a menudo - una clara adaptación a los condicionamientos del medio físico" (Bosque Maurel, J., 1988).

A estos condicionamientos responde, por una parte, como se ha señalado ya, la altitud hasta el que llega el hábitat, así como su disposición en aglomeraciones compactas, de escaso tamaño y limitadas a las solanas de los diversos valles; unos pequeños núcleos compactos y cerrados que tienden a agruparse en familias de viviendas más o menos separadas por espacios vacíos, los «barrios», como los tres - alto, bajo y de enmedio- que componen Trevélez y Pitres, o los dos - alto y bajode Válor y Yegen, entre otros (Caro Baroja, 1957). Con el predominio de una trama lógica en la que el escalonamiento de las calles conforme a las curvas de nivel es decisivo, pero en el que no faltan los cortes transversales, de arriba abajo, que rompen mixtilíneamente y en fuerte declive los ejes horizontales. Una disposición que mantiene hasta cierto punto la aparición en altura, por encima de los «pueblos», de un hábitat disperso y temporal, los «cortijillos» propios del verano.

En este hábitat, la vivienda responde a una tipología generalizada en todo el Mediterráneo occidental, tanto europeo como africano. Se trata de una casa-bloque, según la tradicional tipología francesa (Demangeon, 1947), en altura y escalonada según la pendiente, de forma cúbica y grandes chimeneas que resaltan sobre la cubierta plana. Sin embargo, su adaptación al medio serrano propio es muy clara. En primer lugar, los materiales son los propios de la montaña y obtenidos de su roquedo: blo- 

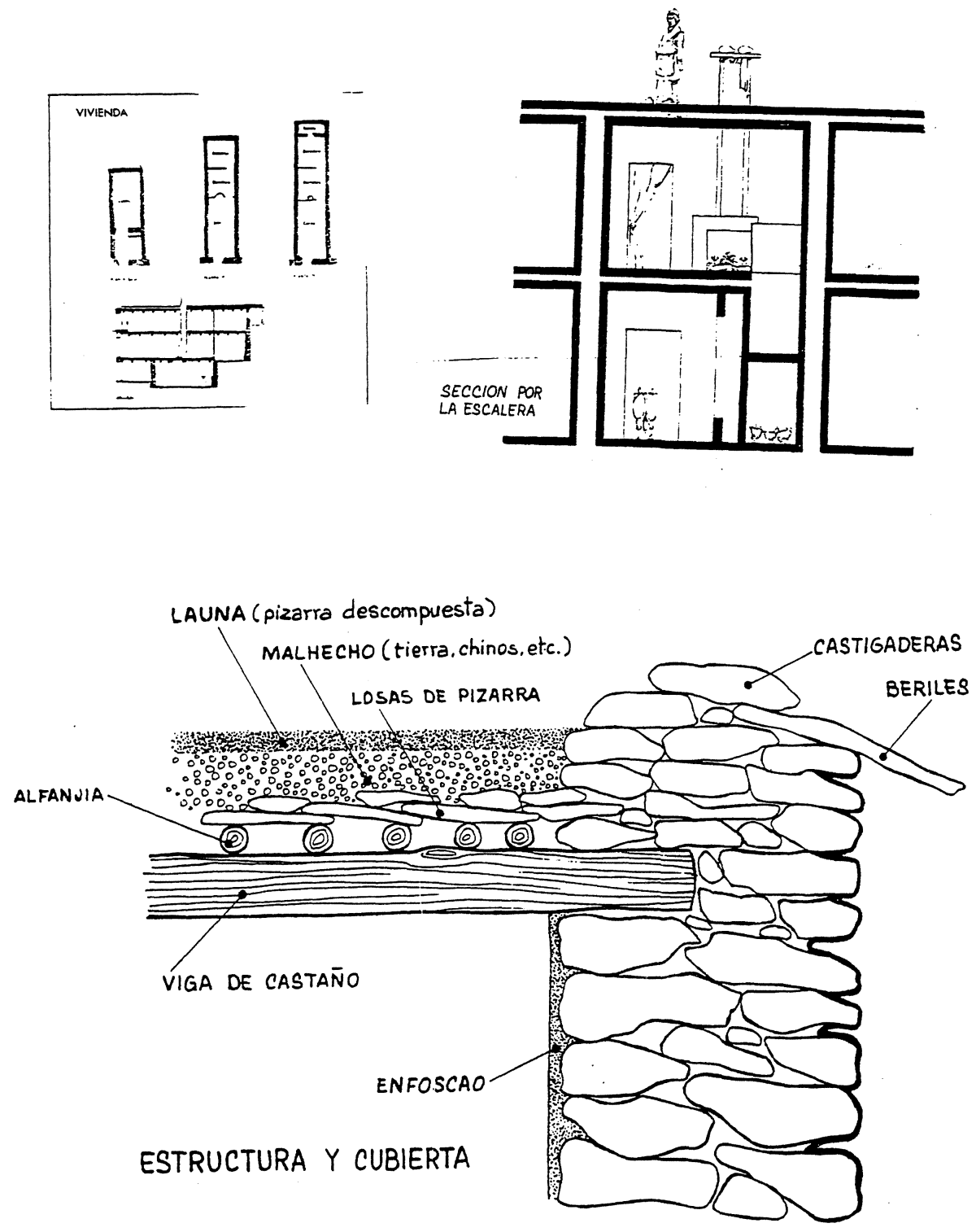

FIG. 6.-La vivienda tradicional en la Alpujarra. 
ques de micasquisto y gneis desiguales en tamaño y forma para los muros embastados con una mezcla de yeso, arena y arcilla, tan abundantes por todas partes; lajas de pizarra esquistosa para los aleros, los pavimentos y las techumbres interiores; troncos y gruesas ramas de roble y castaño, a veces encinas o pinos, para armar los techos y los suelos cuadrados, y «launa», una característica arcilla local verdiazul, plástica e impermeable, para las cubiertas de las terrazas/terrados, que se asientan y cubren el «malhecho», masa compacta de tierra y guijarros que forman el verdadero techo exterior encima de la armadura superior de troncos y pizarras.

Precisamente, según Sermet (1951), la fácil impermeabilización de estos terrados debido al uso de la «launa» es la base de la extensión a toda la Sierra desde el Mediterráneo hasta las cumbres de este tipo de cubierta. En la alta montaña la frecuencia y el volumen de la nieve y su consiguiente elevada humedad podrían haber exigido otra techumbre diferente, como el tejado o dos o más vertientes presente en el entorno serrano, donde la «launa» escasea o falta, y que, sobre todo, en la $\mathrm{Al}$ pujarra sólo cubre las iglesias y algunas casonas pertenecientes a familias pudientes y poco numerosas. El terrado de «launa», sometido a los fuertes cambios térmicos propios de la Sierra, ofrece la ventaja de su plasticidad y de su fácil compostura en caso de grietas crioclásticas. Una simple escoba de fuertes raíces es la solución, que también protagoniza el derrame inmediato a la calle de la nieve caída sobre la aldea, abundante a veces pero no en exceso frecuente.

El tamaño y la disposición interna e, incluso, externa responden tanto a las bases socioeconómicas comarcales como a su condición de instrumento agrario. Su volumen, en general reducido, está en relación con el predominio de unas economías familiares de escasa dimensión por el minifundio y el autoconsumo. Sólo algunas casas de mayor tamaño y, a veces, con más de tres plantas hablan de algunos campesinos, no muchos y en disminución, de mayor riqueza y casi siempre rentistas absentistas que acostumbran a residir en las ciudades inmediatas y sólo temporalmente, durante el verano, vigilan —vigilaban- en la Sierra la mayor actividad agraria.

La distribución en altura, aprovechando el fuerte desnivel de las pendientes, causa del escalonamiento del hábitat, implica y favorece en uso diferenciado de la planta media, como vivienda, de la inferior, como cuadra del ganado de trabajo y el averío, casi el único estabulado 
en los pueblos, ambos con entrada común o no por la fachada delantera, con una tosca escalera sin pasamanos que conduce a la planta media, y del último y superior, como granero y henil, con acceso a menudo por la calle posterior situada a un nivel más alto. La casi total ausencia de corrales en los núcleos de población se explica por la escasez de ganado mayor y por su cría, cuando existe, al aire libre o en una semiestabulación en los «cortijillos» diseminados por las cercanías, a veces más lejos, de los pueblos.

La funcionalidad de la vivienda se percibe también en algunos rasgos externos: los secaderos de frutos y hortalizas orientados y abiertos a la intemperie, los balcones, más frecuentes en las zonas más bajas, en contraposición a las escasas y pequeñas ventanas de doble cierre en madera de las áreas más elevadas, los «tinaos»o «tinados», porches y cobertizos de fachada o que cubren el ancho de la calle, a fin de proteger la carga y descarga de las «bestias» de la lluvia, la nieve y el mal tiempo, y el mismo uso de los terrados bien como secaderos de leña, heno o grano durante el buen tiempo, o como lugar de reunión y tertulia de la población femenina o de la masculina sin condiciones de trabajo o en los momentos de «estación muerta». El encalado que hoy caracteriza a todos los pueblos serranos no es seguro que existiese siempre de forma generalizada; quizás sea un modernismo ya añejo, anterior a 1936, pero consustancial hoy con el encanto del paisaje, a diferencia de otros elementos más recientes, el cemento y la uralita, que ha penetrado con el retorno o la inmigración de los últimos tiempos y ha adulterado y afeado el paisaje serrano.

En fin, una arquitectura «popular», original, auténtica y funcional, que responde a una sabiduría intuitiva transmitida de generación en generación y perfectamente adaptada a las exigencias y limitaciones del medio físico y a las necesidades de una sociedad agraria y tradicional. Tan bien adaptada que, incluso, ahora, en los últimos decenios de regresión demográfica y abandono del terruño campesino, las nuevas actividades, en concreto el creciente turismo, y no sólo por motivos institucionales y culturales sino por razones económicas y funcionales, están procurando, con mayor o menor acierto, la continuidad de todos o casi todos los rasgos tradicionales del hábitat serrano a través de una arquitectura «culta», profesionalizada y formada en el exterior. Los ejemplos son numerosos, resaltando algunas actuaciones en el Barranco de Poqueira, como la «Villa Turística» de Bubión. Y que contrasta con la 
profunda crisis, en esencia poblacional pero no sólo, que está sufriendo toda la región y, sobre todo, la Sierra.

\section{Inmigración y emigración}

Todos estos modos de vida tradicionales han permitido al hombre la ocupación, aunque sea de forma laxa y extensiva, de la Sierra. Sin embargo, ya hemos visto que la población, poco numerosa por una parte, sólo llega a permanecer de manera constante hasta una altitud bastante baja y que, probablemente, no habrá sufrido cambios importantes desde hace siglos. Sin embargo, pudiera ser que la despoblación morisca hubiera provocado un cierto retroceso y descenso en altura del regadío medieval —y por tanto del hábitat — que había sido el fundamento de la vida económica de la población previa a la Reconquista cristiana, a la vez que se producían ciertos cambios en el sistema agrícola que, con el riego, se basaba en la explotación del moral y la morera y la producción y exportación de seda de gran calidad. Así lo intuyó y señaló Garrad (1956). Tras la guerra de los moriscos y su expulsión no cabe duda que la cultura y el cultivo de la seda, como la típica horticultura medieval, sufrió un rudo golpe que condujo a la larga a su desaparición actual.

En cambio, parece ser que los pisos superiores al regadío sólo recientemente han sido conquistados por el hombre e incorporados, más o menos temporalmente, al ecúmene. Según Sermet (1942), esta expansión en altura fue consecuencia de la expulsión de los moriscos a finales del siglo xvi y de la subsiguiente repoblación con cristianos viejos llegados de fuera del Reino de Granada. Entonces, los nuevos habitantes, poco prácticos en la arboricultura y horticultura musulmanas de que nos hablan los viajeros y geógrafos medievales (Simonet, 1872), introdujeron formas de explotación comunes a la Meseta y esencialmente cerealistas que transformaron el paisaje e, incluso, desencadenaron la erosión del suelo. Paralelamente, con precedentes ligados a la misma Conquista del Reino, surgieron formas de organización comunitaria para el uso de los espacios forestales y pastoriles que presentan peculiaridades específicas, sobre todo en el Noroeste de Sierra Nevada, y más concretamente en el municipio de Güejar Sierra, es decir en la cabecera del río Genil, extendida desde el pico de Vacares al Veleta (Martínez

$$
-230-
$$




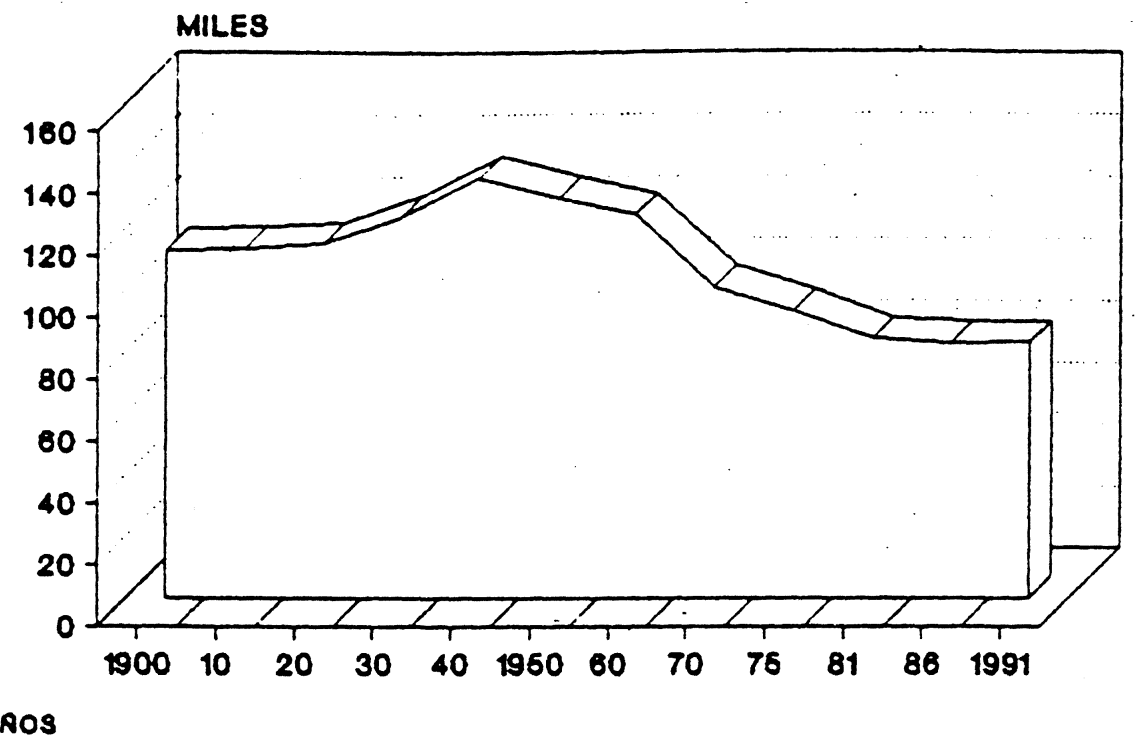

FIG. 7.-La evolución de la población en Sierra Nevada (1900-1991). (Según Cózar Valero y Arias Abellán.)

Lumbreras, 1921, y Luque Baena, 1974). Después, con el tiempo, los primitivos y escasos colonos - unas 2.300 familias, poco más de 11.500 personas en todo el Reino (Núñez de Prado, 1753, y Barrios y Birriel, 1986) - llegaron a multiplicarse por diez, naciendo una presión demográfica que impulsó a la ocupación de las regiones serranas más eleva'as con esa típica actividad mixta agropecuaria de carácter pendular selada.

' ‘a total ocupación de un medio físico ingrato y poco acogedor inentaría la presión demográfica y haría surgir, en la segunda mitad 'lo XIx y primera del actual, un máximo demográfico, quizás se po-

blar de superpoblación -96.374 en 1860, 88.464 en 1900, 85.939 . 920 y 94.604 en 1950 - , que acabaría, al no surgir nuevos modos de vida resolutivos, por provocar un creciente éxodo rural. En todo caso, sí es cierta la existencia de una tendencia emigratoria que ha dado en los últimos años a la población serrana una evidente movilidad regresiva; entre 1950 y 1970, Sierra Nevada disminuyó en población absoluta, a pesar de que, en esta región, el crecimiento vegetativo, dado por el saldo en- 
tre el número de nacimientos y el de defunciones, era todavía en esos años positivo, un hecho que cambió totalmente en los decenios posteriores, dando lugar a un envejecimiento creciente y acelerado de la población, cuyo índice de crecimiento es uno de los más bajos de España. Así, frente a los 94.604 habitantes de 1950, hay que oponer los 63.367 de 1970 y, más aún, los 48.881 de 1991. Una evolución secular en cuyo análisis no se han tenido en cuenta los municipios del borde noroccidental serrano del Parque (Dúrcal, Gójar, Lanjarón, Lecrín, Nigüelas, Padul y La Zubia).

Todo ello revela, en conjunto, una constante emigración - ya en regresión-, un cierto retorno y una incipiente inmigración que ha llegado a crear, sobre todo en la Alpujarra, una apertura muy característica y costumbres nuevas y originales. La corriente emigratoria ha ido a beneficiar a regiones españolas y extranjeras muy diversas y distantes. En España, Cataluña y las regiones industriales del Cantábrico van en cabeza, seguidas por Madrid y su entorno, las regiones de rica agricultura de la depresión penibética y del valle del Guadalquivir, y naturalmente por la capital provincial. En 1950, ya vivían en Granada más oriundos de algún pueblo de la Sierra que en el mismo municipio originario (Floristán, A., y Bosque, J., 1957) y la situación no se ha modificado en 1991, sino todo lo contrario. Fuera de España, el Norte de África y América del Sur - Argentina y Chile - fueron hasta hace algunos años las regiones de máxima atracción aunque más recientemente ha sido Europa Central -Francia, Suiza y Alemania - la esencial receptora de la emigración granadina y serrana (Carvajal Gutiérrez, 1979). Hechos perfectamente contrastables son el elevado número de actuales vecinos serranos -alpujarreños en gran medida- que pueden referirse a sus experiencias viajeras y profesionales en países muy distantes de Europa y América o las numerosas inversiones que los emigrantes retornados han realizado o están realizando en sus lugares de nacimiento (Navarro, 1979, y Cazorla, 1981).

La emigración es relativamente reciente. Y no parece que tienda a detenerse, aunque sí a amortiguarse. En realidad, el espíritu andariego y el gusto por la aventura, muy comón entre los montañeses, parece haber estado presente siempre entre los habitantes de la Sierra y haber incluso superado a la misma necesidad. En todo caso, el retroceso demográfico que, según Rodríguez Martínez y Arias Abellán (1996), alcanzó su culminación en la década de los cincuenta con una pérdida 


\section{PIRAMIDE DE SIERRA NEVADA} 1991

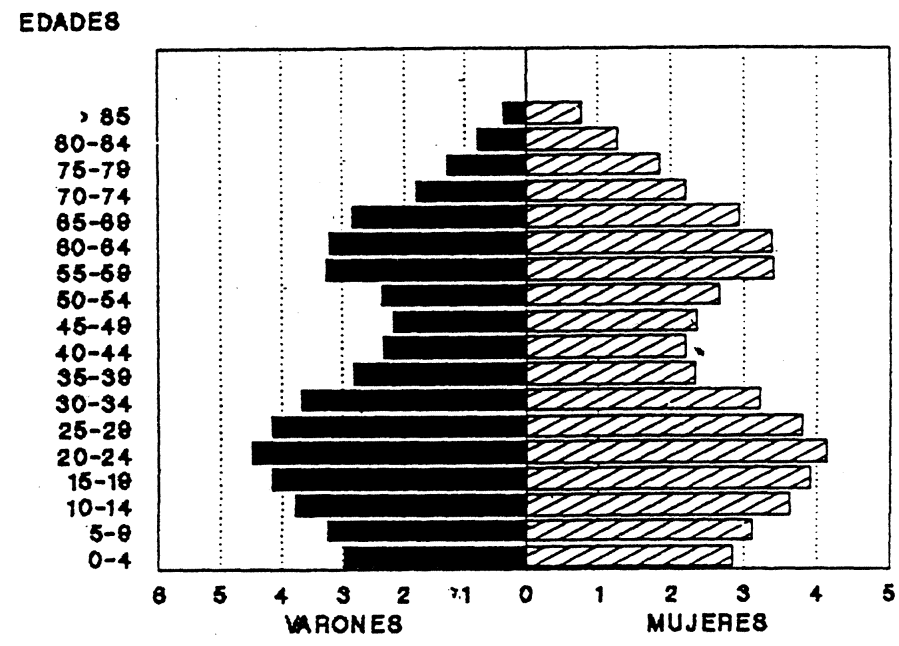

Fig. 8.-Pirámide de edad de Sierra Nevada (1991). (Según Valero y Arias Abellán.)

anual de 5.275 habitantes, ha ido descendiendo poco a poco en los años siguientes, recuperándose algo la población a partir de 1986 y ofreciendo cifras positivas en el quinquenio 1991-1995, con un millar de incremento anual. Aunque, afirman dichos geógrafos, el «aumento es, en cierto grado, ficticio..., ya que si bien se ha detenido el proceso migratorio y hay algunos retornos, lo sustancial del mismo se debe al desarrollo de algunos municipios periféricos en el área de influencia de la capital (Monachil sobre todo)»(1996). Además, la recuperación poblacional presenta grandes dificultades internas, debido sobre todo al fuerte envejecimiento de la población serrana que, en el conjunto municipal del Parque, asciende a un $16,16 \%$ de más de 64 años, frente a un porcentaje del 12,74 para la provincia de Granada y del 11,62 para Almería, y que está acompañado por una baja tasa de crecimiento vegetativo, el 0,88 de media anual en el período 1986-1990, resultado de una natalidad del 11,18 y una mortalidad del 10,30 (Arias Abellán, J., y Cozar Valero, 1996). 
Para limitar esta emigración, o provocar una tendencia contraria, sería necesario crear, recrear más bien, una economía distinta a la tradicional agropecuaria o forestal, pero esta nueva economía apenas se encuentra ahora en sus comienzos. Entre estas nuevas actividades, que siguen mirando más hacia el exterior que hacia el interior de la Sierra, y muchas veces son simples reflejos de la vida que está cambiando en las regiones periféricas, cabría destacar la minería, la explotación hidráulica y, en último término, por ser la más joven, el turismo que, acaso, pudiera convertirse, bien dirigido, en la varita mágica que transformase por completo la mortecina vida de Sierra Nevada.

\section{Las nuevas posibilidades económicas}

Entre estos nuevos horizontes de trabajo, la minería es sólo moderna por los procedimientos y los objetivos actuales, y vieja por lo que siempre ha significado en la vida de la Sierra. En el pasado, hasta principios del siglo XIX, únicamente la explotación aurífera -Estrabón se refiere a «minas de oro en Sierra Nevada» (Cohen Amselem, A., 1998)—alcanzó cierta trascendencia; en cambio, a partir de 1825, en que se promulgó la primera Ley de Minería se produjo cierto rápido desarrollo no sólo en cantidad, sino también en calidad, de otros aprovechamientos. Entonces, el trabajo del oro quedó limitado al aprovechamiento más o menos rudimentario de las arenas de los ríos, y se fueron agregando actividades de gran importancia y extraordinaria intensidad, entre las que se destacaron el beneficio del plomo y del hierro.

Primero, a mediados del siglo XIX, los viejos placeres auríferos de los ríos Darro y Genil sufrieron una profunda transformación a consecuencia del establecimiento de una empresa francesa en el Cerro del Sol, muy cerca del borde de la Sierra y próxima a la Ciudad de Granada, que trató, sin mucho éxito, de aprovechar los aluviones de las regiones serranas periféricas mediante una minería «hidráulica». Hoy el oro es apenas un recuerdo y una leyenda que aún atrae a algunos buscadores a las márgenes del Darro, y, en muchos casos, es un atractivo más o menos novelesco en una rápida visión de la ciudad de Granada (Ortí Serrano, 1961).

Mayor importancia tuvo el plomo en este despertar minero del siglo pasado. Madoz (1987) cifraba en 59 las minas de plomo y en cinco las de 
plata en 1842. En 1875, existían 78 minas de plomo repartidas por toda la provincia, y en su mayor parte situadas dentro de los límites de la Sierra, en los municipios de Jeres, Lanteira y Aldeire, al N y Quéntar y Dílar, al SO, entre otros. Desde 1950, la minería del plomo, que llegó a contar, hace muchos años con fundiciones en Baza y Motril, aparecía limitada a las cadenas montañosas de la Costa, a la sierra de Lújar concretamente, origen de una pequeña producción remitida a las fundiciones de Linares y Málaga y paralizada en 1988. En una línea similar puede situarse la explotación del azogue iniciada en 1869 en Cástaras y Albuñol, que tuvo su apogeo con la constitución de la compañía inglesa «The United Meraun Mines of Granada Ltd.» en 1903 y terminó a mediados de este siglo (Cohen Anselem, A., 1998).

Pero, tanto el oro como el plomo y el azogue, fueron desplazados, tras la guerra civil, por la minería del hierro, en la que la provincia de Granada llegó a ocupar el tercer lugar en España, con una producción que se aproximaba, en los años setenta, al millón y medio de toneladas y era la base de una importante exportación. El principal criadero, ya hoy prácticamente agotado, se encuentra en el borde inferior de la vertiente septentrional de la Sierra, en Alquife, en el Marquesado del Zenete, a más de mil metros de altitud, y estaba formado por dos grandes explotaciones diferentes. La primera en el tiempo, se han encontrado restos arqueológicos romanos, inicialmente fue aprovechada por una sociedad inglesa (The Alquife Mines \& Railway Co.Ld.) constituida en 1899, pero que pasó finalmente a depender (1953), hasta su cierre, de la siderurgia española, de Altos Hornos de Vizcaya. La segunda, la Compañía Andaluza de Minas, algo posterior (1929), estuvo desde el primer momento ligada al capital francés. Convertida en una modélica explotación a cielo abierto, llegó a obtener en los años setenta en torno a tres cuartos de millón de toneladas, pero en los noventa ha entrado en un rápido declive que ha concluido en su reciente abandono por la empresa madre y en el intento de reapertura a partir de los trabajadores, que han constituido una cooperativa, y la ayuda de la Comunidad andaluza. El mineral de Alquife, de ambas explotaciones, salía de la región por un doble ferrocarril minero que enlazaban en La Calahorra y Huéneja con la vía férrea Madrid-Baeza-Guadix-Almería. Desde los grandes cargaderos instalados en el puerto de esta última ciudad era enviado hasta las siderurgias centroeuropeas primero y a las españolas del Cantábrico después. 
En el mismo Marquesado, en Huéneja, se encuentra otro conjunto de criaderos ferríferos, mucho menos importantes y que cesó en sus actividades hace más de veinte años. La Sierra, en su vertiente meridional, alpujarreña, cuenta con el único yacimiento terrífero capaz de rivalizar hasta cierto punto con los del Marquesado, el existente en el Cerro del Conjuro, en el municipio de Busquístar, aunque con muy difíciles condiciones de transporte - un funicular- y salida por el puerto de Motril. Tuvo un cierto período de explotación positiva, en los años sesenta y setenta, apoyado en el Instituto Nacional de Industria, que condujo a su cierre definitivo a finales de esta última década (Cohen Amselem, A., 1987 y 1998).

Ni el oro, ni el plomo, ni el azogue, ni tampoco el hierro, son las únicas riquezas minerales de Sierra Nevada. Su complejidad geológica justifica su extraordinaria variedad mineralógica, que hoy no tiene más problema que el de ser mal conocida, estar muy mal valorada y carecer de fáciles comunicaciones. Puede recordarse la gran variedad de mármoles de gran calidad y sus numerosas piedras finas, ágatas, serpentina, existentes en la Sierra, y que hoy, como en el pasado, embellecen los más bellos monumentos artísticos de la ciudad del Genil, aparte de haber facilitado el desarrollo de ciertas actividades fabriles, como la fabricación de piedra artificial, por ejemplo, ubicadas en los polígonos industriales granadinos.

Más reciente ha sido el nacimiento de la energía hidroeléctrica, una riqueza que ha sido calificada acertadamente para el conjunto de la provincia de «hidroelectricidad en pequeña escala» (Núñez Romero-Balmas, G., 1998) y que lo es aún más para Sierra Nevada, precisamente la porción de Andalucía Oriental con mejores condiciones para la existencia y el desarrollo de esta energía. La primera central eléctrica serrana se construyó en 1897 precisamente en Pinos Genil, a 774 metros de altura, a pocos kilómetros de Granada y en la parte inferior del Alto Genil, siendo después numerosos los saltos construidos en los cursos fluviales nacidos en la Sierra, las dos centrales de Monachil, en 1904 y 1907 respectivamente, la de Diéchar, en 1917, la de Dílar, en 1920, las de Dúrcal y Güejar Sierra, en 1923, y las de Pampaneira y Capileira, ya en la Alpujarra, más recientemente, en 1958. En total, el conjunto de todos los ríos de la Sierra, con una potencia instalada de $39.975 \mathrm{Kw}$, produce unos 180 millones de Kwh, apenas la centésima parte de la energía española y mucho menos del consumo de la región. No es precisamente 
una masa extraordinaria, ni siquiera proporcional a la significación territorial y altitudinal de nuestra cordillera y de la ya tópica afirmación de la Sierra como «una gran arca de agua». Tal escasez parece ser consecuencia del reducido caudal de dichos cursos fluviales y, sobre todo, de su irregularidad muy acusada, así como de la difícil coordinación de estos aprovechamientos con las crecientes necesidades de los regadíos, tanto de la Sierra como de las Depresiones periféricas (García Romanillos, 1955).

Esta energía eléctrica beneficia, ante todo, a las regiones no serranas, de donde han surgido las iniciativas y los capitales creadores de las instalaciones hoy en funcionamiento. Así, se explica el predominio que, en este terreno, tiene la vertiente septentrional productora de los dos tercios de dicha fuerza eléctrica y abastecedora en cierta medida de Granada ciudad, cuyas necesidades dieron origen a la industria. Pero en cambio, esta energía no ha sido capaz, hasta el momento, al menos, de favorecer el desarrollo industrial, ni siquiera revitalizar una economía de montaña, hoy en decadencia si se tiene en cuenta la creciente presión de la población, lo mismo que ha hecho en otras regiones de Europa, como los Alpes, el Jura o el Macizo Central francés. Recuérdese, a este efecto, la importancia que en la industria relojera suiza tienen los pequeños talleres artesanos de sus valles alpinos, productores de más de las dos terceras partes de las piezas luego ajustadas por los grandes talleres de Ginebra, Le Locle o Le Chaux de Fonds. Y, no hay que ir al extranjero para encontrar un ejemplo a seguir, ya que el Pirineo aragonés ha presenciado, desde los años cincuenta, un claro incremento industrial, fruto en cierta medida de su potencia y su desarrollo hidroeléctrico (Daumas, 1962).

Finalmente, es el turismo la única actividad que, en verdad, está transformando Sierra Nevada, y más concretamente su porción NO, donde adosada al Veleta, en la cabecera del río Monachil, se encuentra la estación invernal Solynieve, la más meridional de Europa. Su situación, a mitad de camino entre Granada y la Costa del Sol, ha convertido en plena realidad el «slogan» de que Granada reúne «los atractivos turísticos de Ischia, Cortina d'Ampezzo y Florencia» (Gallego Morell, 1961). Tras un período de iniciación individualista y de ámbito muy limitado, anterior a 1936, que estuvo ligado a la construcción del ferrocarril de vía estrecha de la Sierra bajo el patrocinio del duque de San Pedro de Galatino, a la promoción de la carretera al Veleta por Juan José 


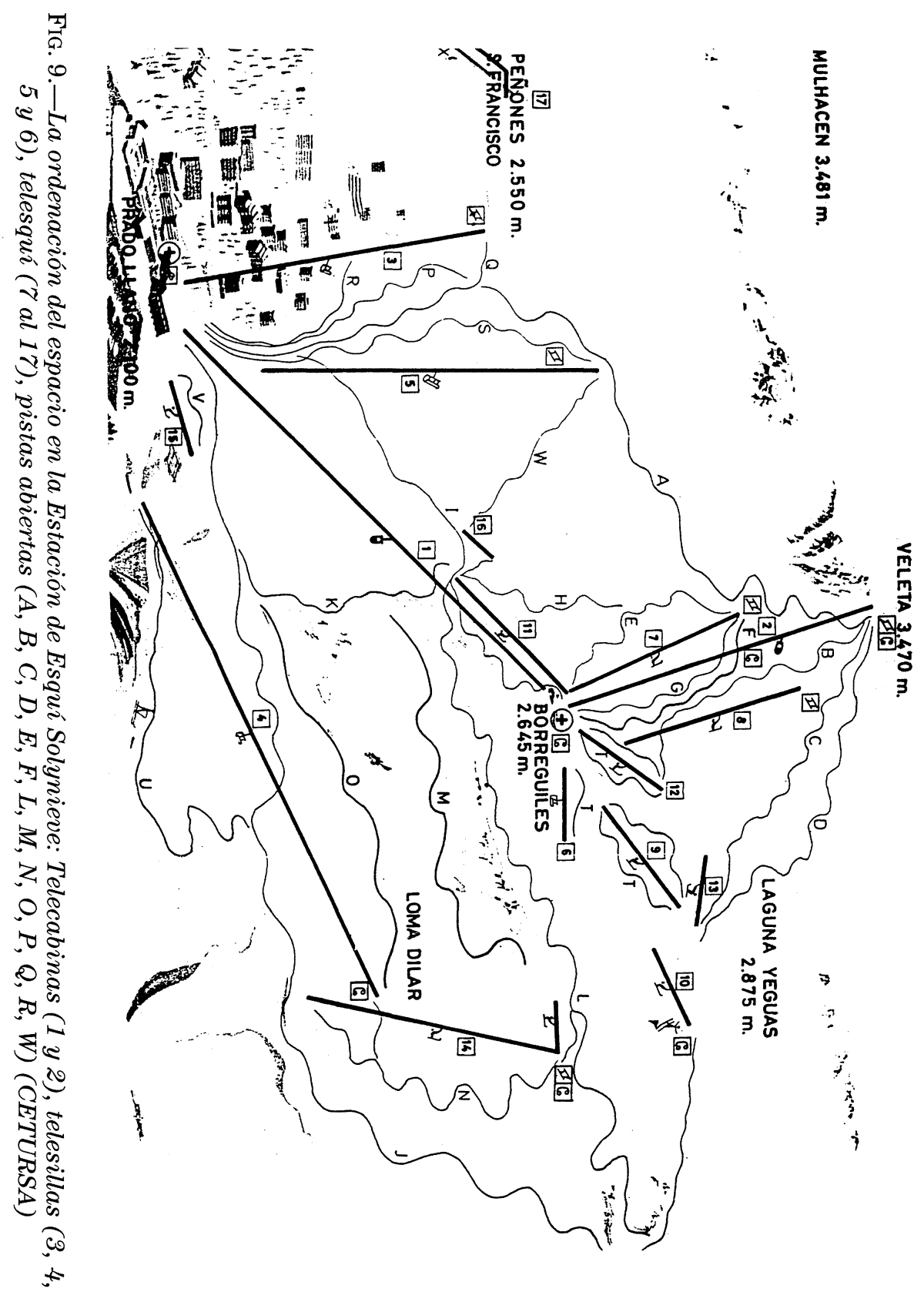

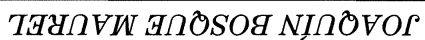


Santa Cruz, y a los primeros albergues de montaña, entre los que se destaca el Universitario, inaugurado en 1934, el gran desarrollo turístico tuvo lugar después de 1960, con la compra por el Ayuntamiento de Granada, de la dehesa de San Jerónimo (1962), y la aprobación de un Plan Municipal de Ordenación Turística y Deportiva, plenamente desarrollado.

La gran Estación Invernal que se deriva de ese Plan, ha sido llevada a cabo por CETURSA (Compañía de Centros Turísticos, S. A.), concesionaria por concurso y ejecutora desde 1964 del Plan. De él se han derivado cuatro núcleos principales: a) la zona residencial y hotelera de Prado Llano, b) el área deportiva de Borreguiles, unida a la anterior mediante telecabina, c) la Laguna de las Yeguas, de servicios y deportiva, y d) la Carihuela del Veleta, de valor exclusivamente deportivo. Un conjunto ligado entre sí por un complejo sistema de rutas, telecabinas y telesillas. Aparte, en el interfluvio que separa esta área deportivo-residencial del Monachil del barranco de San Juan, cabecera del Genil, se encuentra la zona tradicional de la Hoya de la Mora, apoyada en los primeros Albergues de alta montaña, anteriores a 1936, y en el Parador de Turismo inaugurado en 1966, y menos desarrollada, pese a las muchas posibilidades que le ofrece su situación junto a la carretera y cerca del gran «corral» glaciar del Veleta.

El futuro deportivo de Sierra Nevada, pese a sus problemas climáticos relacionados con el momento de la llegada y la escasez o abundancia de la nieve, es indiscutible, sobre todo como estación invernal, como ya ha llegado a demostrar la celebración en 1997 de la Copa del Mundo de Esquí, siendo menores las posibilidades estivales, que exigen condiciones físicas poco desarrolladas aún, aunque presentes (Ariza Rubio, 1984 y 1992, y Titos Martínez, 1997). Pradollano disponía, en 1996, de 2.711 plazas hoteleras que han alojado en los últimos períodos a un volumen medio diario de unas 10.000 personas durante la estación invernal, aunque el número total de visitantes ascendió en 1993-1994 a $735.279,114.954$ visitantes stricto sensu y 620.325 esquiadores, una cifra que en 1995-1996 se convirtió en 835.959 (Titos Martínez, 1997).

No es la nieve ni el esquí la única posibilidad de ocio y turismo existente en Sierra Nevada. El montañismo y el senderismo, gracias a las bellezas naturales serranas, a sus condiciones para la escalada y la riqueza y diversidad biológica, constituyen un objetivo a desarrollar, lo mismo que el descanso y el ocio especialmente estival, actividades en las 
que la vertiente alpujarreña tiene tradición y puede alcanzar un gran protagonismo. En todos ellos cabe esperar un decisivo impulso de los Planes Leader decididos por la Unión Europea y tan claramente avocados a un desarrollo sostenible que debe extenderse a toda la Sierra y no limitarse a unos pocos núcleos: Poqueira (Villa Turística de Bubión), Trevélez, Lanjarón, y poco más.

La tendencia es claramente ascendente como puede demostrar la casi duplicación del alojamiento hostelero producido en el conjunto de la Alpujarra entre 1972, con 1.254 plazas, casi exclusivamente en Lanjarón (1.237), y 1996, con 2.087 plazas, momento en que, junto al retroceso hotelero de Lanjarón (1.049), aparecen otros núcleos en Bubión (170), Capileira (98), Orjiva (143), Pórtugos (101) y Trevélez (77). Una vía, el turismo global, que debe tener muy en cuenta las posibilidades del conjunto de Andalucía, en especial del atractivo de Granada, pero no menos la realidad del Parque Natural/Nacional de Sierra Nevada.

Ahora bien, todos estos modos de vida no campesinos aún no han afectado seriamente al hecho geográfico de Sierra Nevada. A lo más han comenzado a transformar determinadas áreas serranas, con lo que son meros matices, simples accidentes, en una esencia tradicional que subsiste íntegra. La Sierra sigue siendo, a diferencia de otras cordilleras españolas y, sobre todo, en relación a las grandes montañas alpinas mediterráneas, una cordillera de campesinos. Aunque según el último Censo de 1991, la estructura de la población activa ha sufrido una clara convulsión respecto a 1981. Mientras en esta última fecha, el sector agrícola significaba el 68,1\% del total, en 1991 había descendido al 28,8\%; en contrapartida, los servicios habían pasado del $20,5 \%$ al $45 \%$, habiendo sido menor el incremento de las actividades secundarias, 11,3 y 25,6 respectivamente (Arias Abellán, J., y Cozar Valero, E., 1996).

\section{El Parque Natural/Nacional de Sierra Nevada}

En realidad, ninguna de las actividades últimamente desarrolladas ha conseguido transformar en su totalidad la imagen tradicional de Sierra Nevada: una alta montaña escasamente poblada y hasta poca altitud, dominada por una agricultura similar, aunque en retroceso, a la de sus regiones periféricas y apenas penetrada por modos de vida típicamente montañeses, como la ganadería, y, en los últimos decenios, la hidroe-

$$
-240-
$$


lectricidad y el turismo. Si la relación con las montañas europeas es limitada, el parecido con el Atlas sigue siendo evidente (Despois, 1967, e Isnard, 1979). Y las posibles causas pueden ser muchas, unas de índole física, otras, las más, de raíz humana e histórica. Sin embargo, el futuro de la Sierra exige su transformación, su conversión a actividades, a horizontes de trabajo nuevos y revolucionarios, que detengan la emigración y saquen a la región de ese lugar en que se encuentra últimamente, uno de los últimos en la lista de las provincias españolas por su renta por habitante.

Ahora bien, en toda futura consideración de Sierra Nevada no deberá olvidarse nunca que la cordillera más alta de la Península no es un hecho geográfico aislado. Su conformación física y su vida humana, como la de cualquier otra montaña, está íntimamente ligada a las comarcas que la rodean y con las que tiene indudables puntos de contacto y convivencia. Sierra Nevada no puede ser separada de la Costa, ni del valle del Lecrín, ni de las Vegas interiores de Granada, Guadix y Baza, con las que forma, como con todo el Mediodía español, una completa y compleja unidad geográfica que sería peligroso, sino imposible, romper, y que tiene su culminación, paradigmática, en la Ciudad de Granada.

Pero, tampoco es conveniente poner en peligro su identidad física y humana, su riqueza material y formal, su indudable personalidad ecológica, su rica tradición. Por ello, desde muy pronto, se planteó su defensa y conservación a toda costa (Bosque Maurel, J., y Ocaña Ocaña, M. ${ }^{a}$ C., 1970, y Bermúdez Cañete, 1981) y, en definitiva, tras una larga y nada fácil andadura política y social, su declaración, primero, de «Zona Natural de Protección Universal» por la UNESCO, a través del Programa MAB (Man and Biosphere), en 1986, después, de Parque Natural por la Junta de Andalucía en 1989, y, finalmente, su conversión en Parque Nacional ante las Cortes Generales y el Gobierno central de España en 1997.

El Espacio Protegido de Sierra Nevada, el tercero en extensión en la red andaluza de Parques, comprende un total de 171.646 has repartidas entre las provincias de Granada (119.009 has) y Almería (52.637) y entre sesenta municipios de ambas provincias, y que afecta a las altas cumbres de la Sierra, desde aproximadamente los 1.200 metros de altitud. La gestión del Parque corresponde a la Junta de Andalucía, a través de la Consejería de Medio Ambiente, y mediante los Planes de Ordenación de Recursos Naturales (PORN) y de Uso y Gestión del Parque Natural (PRUG) de Sierra Nevada, aprobados con cierta demora en 1994. 


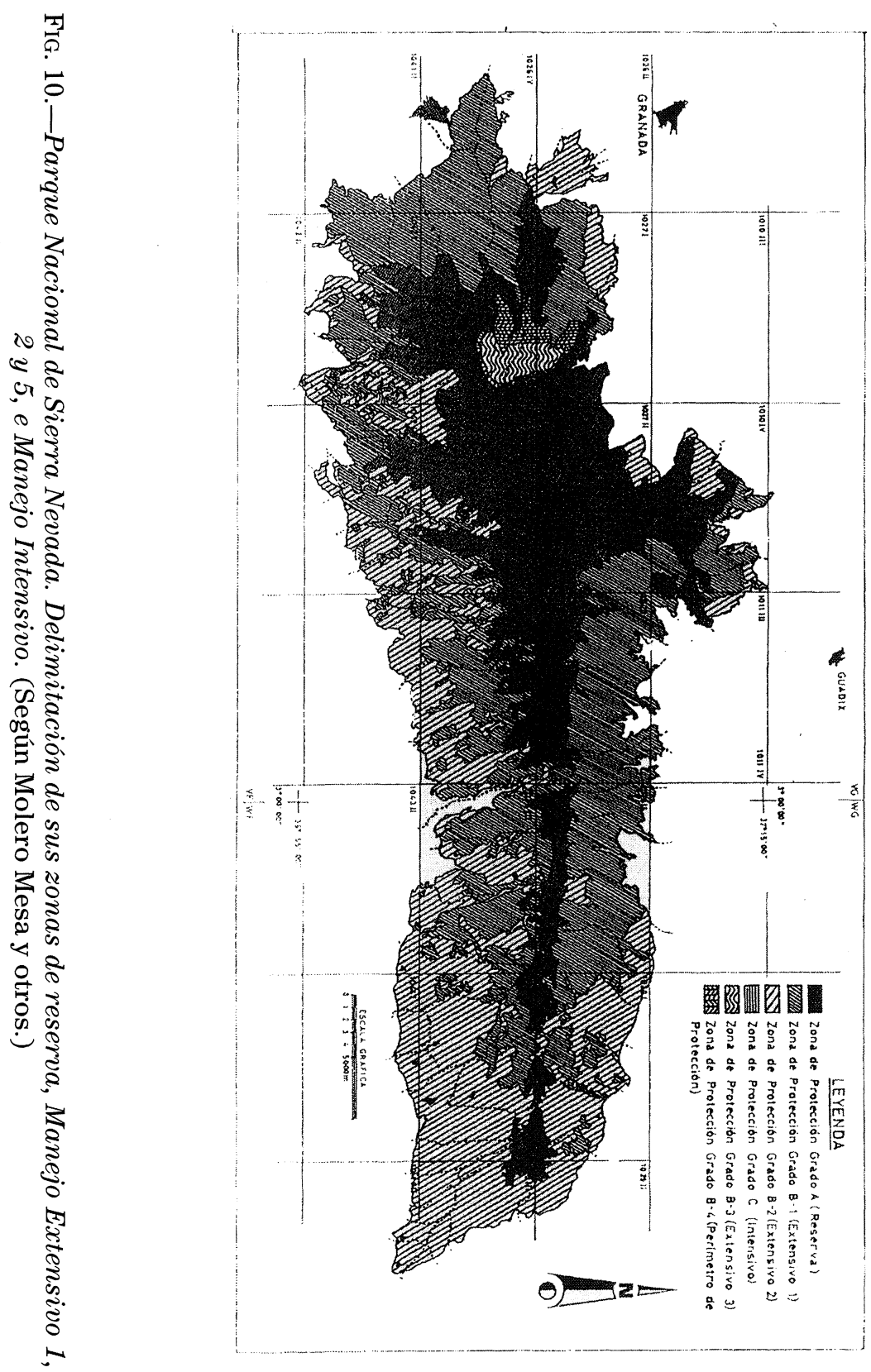

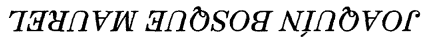


Los objetivos principales del Parque son a) proteger los ecosistemas de gran interés ecológicos ligados, entre otros, a los pisos bioclimáticos supra, crio y oromediterráneos, conservar los recursos hídricos, edáficos, faunísticos, florísticos y, en especial, los endemismos existentes, y garantizar su diversidad biológica; b) ordenar los aprovechamientos tradicionales que persistan y el uso social y educativo del Parque, compatibilizándolo con la conservación de los recursos naturales, c) propiciar el conocimiento y divulgación de los valores del Parque, favoreciendo la investigación sobre su ingente concentración de endemismos, d) mejorar las condiciones socioeconómicas de los municipios incluidos en su área de influencia, promoviendo el desarrollo sostenible de los mismos, y e) incorporar a la red de Parques Nacionales la muestra más significativa y representativa de formaciones y ecosistemas de media y alta montaña mediterránea de la Península Ibérica (Molero Mesa, J., y otros, 1992, y Rodríguez Martínez, F., y Arias Abellán, J., 1996).

El futuro de Sierra «queda así enmarcado en este contexto político» de defensa de la Naturaleza que, a su vez, podría potenciar las posibilidades vitales de un macizo montañoso que se encuentra «en un trance de transformación económica sin precedentes, sobre todo por lo que se refiere a la práctica desaparición de las actividades agrícolas tradicionales» (Rodríguez Martínez, F., y Arias Abellán, J., 1996), pero que, por su situación, su originalidad y sus posibilidades, constituye un factor esencial en el desarrollo, respetuoso y sostenible, de una región, emblemático en muchos sentidos, pero pletórica de problemas. Y que si hoy ocupa por su renta un lugar final en el espacio español, no siempre lo ha estado en el pasado. Lo que permite pensar - y confiar - en un cambio positivo en el futuro.

Y, al menos, podría validar una afirmación, ya tópica, aunque en posible cambio, pero no absoluto, de uno de los más entusiasta valedores y promotores de Sierra Nevada, que, en 1900, casi hace un siglo afirmaba: «Aunque Granada siga figurando en los catálogos literarios con el nombre de ciudad de la Alhambra, no es sólo la melancolía de su pasado morisco, ni la extraña sugestión de sus grandezas muertas, lo que en ella subyuga y la hace patria de poesía y rincón de seductores ensueños. Es la sublime grandiosidad de su Sierra Nevada, que tiene enfrente como inmenso telón de boca, es el poema de la nieve, que corona aquellas cumbres, y del sol, que guarda para ella sus más apasionadas caricias; son los altísimos picos, como islas blancas en el cielo azul, y el en- 
canto de los valles perfumados; los violentos contrastes, la variedad inagotable de sus paisajes, la soberana belleza de sus crepúsculos incomparables, cuando el sol muere entre abismos de fuego y crespones cárdenos, lanzando, como amante insaciable, sus últimos besos a la neveda sierra, que se ruboriza de escarlata». Y, también, no acatar uno de sus asertos finales: «Sierra Nevada es casi desconocida. Guarda en secreto sus tesoros artísticos y sus tesoros materiales. Sólo sirve, desde lejos, como elemento decorativo» (López, N. M. ${ }^{a}, 1992$ ).

\section{BIBLIOGRAFÍA}

ARIAS ABELLÁN, J. (1981): «La repoblación forestal en la vertiente norte de Sierra Nevada», Cuadernos Geográficos Universidad Granada, 11, pp. 283-305.

- (1984): Propiedad y usos de la tierra en el Marquesado del Zenete, Col. Monográfica, 85. Granada, Secretaría de Publicaciones de la Universidad de Granada, 340 pp.

ARIZA RUBIO, M. ${ }^{a}$ J. (1992): «La estación de esquí de Sierra Nevada», en Nuevos paseos por Granada y sus contornos, Granada, Caja de Ahorros, III, pp. 193-210.

BARRIOS AGUILERA, M. (1993): Moriscos y repoblación en las prostrimerías de la Granada islámica. Biblioteca de Ensayo, 26. Granada, Diputación Provincial, 336 pp.

Barrios Aguilera, M., y Birriel Salcedo, M. M. (1986): La repoblación del Reino de Granada después de la expulsión de los moriscos. Granada, Grupo de Autores Unidos y Universidad de Granada, $382 \mathrm{pp}$.

Bermúdez Cañete, F. (1981): «El proyecto de Parque Nacional de Sierra Nevada y la Ordenación Territorial de las Áreas de Montaña», Supervivencia de la montaña. Actas del Coloquio hispano-francés sobre las áreas de montaña. Madrid, Servicio de Publicaciones Agrarias, pp. 477-486.

BoIssier, CH. (1995): Viaje botánico al sur de España durante el año 1837. Estudio preliminar de M. C. Pezzi Ceretto. Col. Sierra Nevada y la Alpujarra, 13. Granada, Fundación Caja de Granada y Universidad de Granada, 406 pp.

Bosque MAUREL, J. (1959): «La producción de mineral de hierro en Sierra Nevada (Granada)», Estudios Geográficos, XX, pp. 148-149.

(1962): Geografía urbana de Granada. Premio Luis Vives. Zaragoza, Instituto de Geografía Aplicada (CSIC), 313 pp.

- (1969): «Minería y agricultura tradicional en el Marquesado del Zenete», Homenaje al profesor Ángel Canellas. Zaragoza, Universidad de Zaragoza, pp. 209-226.

(1971): Granada, la tierra y sus hombres. Granada, Departamento de Geografía de la Universidad de Granada, $347 \mathrm{pp}$.

- (1971): «El hombre y el medio en Sierra Nevada», en Ferrer, M. (Coord.), Sierra Nevada, Granada, Ediciones Anel, pp. 545-551.

- (1979): «Tradición y modernidad en las Alpujarras granadinas (Andalucía)», pp. 89133, en ibidem, Andalucía. Estudios de geografía agraria, Granada, Aljibe, 198 pp. (1982), «Las posibilidades de desarrollo de la montaña mediterránea: El caso de la Serranía de Ronda», Jornadas de Estudios sobre Ronda y su comarca, 8-10 octubre 1979, Madrid, Ayuntamiento de Ronda, pp. 1-15.

(1988): «Paisaje geográfico y equilibrio ecológico en la Alpujarra (Andalucía, España)», Livro Homenaje a Orlando Ribeiro, Lisboa, Centro de Estudios Geográficos, I, pp. 281-295. 
— y OCAÑA OCAÑA, M. ${ }^{a}$ C. (1970): Calificación de Parques Nacionales en la Provincia de Granada. Granada, Consejo Económico Sindical Provincial, 25 pp.

Brenan, G. (1974): Al sur de Granada, Madrid, Siglo XXI de España, Edit., 342 pp.

Bueno PoRCEL, P. (1987): Sierra Nevada. Guía montañera. Granada, Universidad y Diputación Provincial, 564 pp.

CARANDEll, J. (1994): «El hábitat en la Sierra Nevada», pp. 179-264, en ibidem, Sierra Nevada, Montblanch de España y otros escritos. Estudio preliminar de F. Mayor Zaragoza. Col. Sierra Nevada y la Alpujarra, 10. Granada, Caja General de Ahorros, 264 pp.

CARO BAROJA, J. (1957): Los moriscos del reino de Granada. Ensayo de historia social. Madrid, Instituto de Estudios Políticos, $305 \mathrm{pp}$.

Carvajal GutiérRez, M. ${ }^{a}$ C. ( 1986): Población y emigración de Granada en el siglo XX. Granada, Diputación Provincial, 206 pp.

CAZORLA PÉREZ, J. (Coord.) (1981): Emigración y retorno. Una perspectiva europea. Madrid, Instituto Español de Emigración, 328 pp.

Cohen Amselem, A. (1987): El Marquesado del Zenete. Tierra de Minas. Prólogo de P. Vilar. Granada, Diputación Provincial, $525 \mathrm{pp}$.

- (1998): «La minería», en Titos Martínez, M., Historia económica de Granada. Granada, Cámara de Comercio, Industria y Navegación, pp. 173-189.

CozAr VAlero, E., y ARIAS ABELLÁN, J. (1996): «Desequilibrios demográficos, envejecimiento y actividad de la población de Sierra Nevada», I Congreso Internacional Sierra Nevada. Conservación y desarrollo sostenible. Granada, Universidad, Junta de Andalucía, UNESCO, Sierra Nevada, 1996, IV, pp. 291-314.

DAUMAS, M. (1962): «Les consecuènces géographiques d'une implantation industrielle en montagne, la population de Sabiñanigo (Province de Huesca)», Rev. Géographique des Pyrénées et du Sud-Ouest, XXXIII, pp. 325-337.

Demangeon, A. (1947): «Essai d'une classification des maisons rurals», en Problèmes de Géographie humaine. París, A. Colin, 230-238 pp. Traducción española, Barcelona, Omega, 1956).

DespoIs, J., y RAYNAL, R. (1967): Géographie de l'Afrique du Nord-Ouest. París, Payot, 300 pp.

Florisitan SAmanes, A., y Bosque MaURel, J. (1957): «Densidad de población en la provincia de Granada», Boletín de la Universidad de Granada, VI, pp. 89-109.

- (1957): «Movimientos migratorios de población en la provincia de Granada», Estudios Geográficos, XVIII, pp. 301-402.

GARCÍA ROMANILLOS, F. (1955): El problema eléctrico en la provincia de Granada. Granada, Consejo Económico Sindical Provincial, $15 \mathrm{pp}$.

Gallego Morell, A. (1961): «Sierra Nevada y el turismo», Bol. Cámara Comercio e Industria, III, 11, pp. 20-22.

GARRAD, K. (1956): «La industria sedera granadina en el siglo XVI y su conexión con el levantamiento de las Alpujarras (1568-1570), Miscelánea de Estudios Árabes y Hebraicos, V, pp. 73-104.

Gómez OrTiz, A., y SALVADOR Franchi, F. (1996): «Acerca de la génesis y morfodinámica del glaciarismo de Sierra Nevada», I Conferencia Internacional Sierra Nevada. Conservación y Desarrollo sostenible. Granada, Universidad, Junta de Andalucía, UNESCO y Sierra Nevada, 1996, I, 233-260.

HUGUET DEL VILLAR (1921): El valor geográfico de España. Ensayo de ecética, Madrid.

HuRtado DE MendozA, D. (1970): Guerra de Granada. Edición de B. Blanco-González. Clásicos Castalia, 22. Madrid, Castalia, $449 \mathrm{pp}$.

Isnard, H. (1973): Pays et paysages méditerranées. Col. La Géographie, 11. París, PUF. ISNARD, H. (1979): El Magreb. Barcelona, Ariel, $250 \mathrm{pp}$.

LóPez, Nicolás María (1992): En Sierra Nevada. Prólogo de N. López Calera. Col. Sierra Nevada y La Alpujarra, 5. Granada, Caja General de Ahorros, 173 pp. 
LUQUE BAENA, E. (1974): Estudio antropológico social de un pueblo del Sur. Col. Ciencias Sociales. Serie de Sociología. Madrid, Tecnos, $251 \mathrm{pp}$.

MADOZ, P. (1987): Diccionario Geográfico-estadístico-histórico de España y sus posesiones de Ultramar. Granda. Facsimil de la edición de 1845-1850. Estudio introductorio de Joaquín Bosque Maurel. Valladolid, Ámbito Ediciones, S. A., 321 pp.

MARTínez Lumbreras, F. (1921): «El Derecho consuetudinario en la provincia de Granada. La Junta Comunal de Güejar Sierra», Rev. Centro Estudios Históricos de Granada, XI, pp. 41-71.

Messerl, B. (1965): Beiträge zur Geomorphologie der Sierra Nevada (Andalusien). Zurich, 178 pp. y 20 láminas.

Molero Mesa, J.; Pérez Raya, F. y Valle Tendero, F. (Coords.) (1992): Parque Natural de Sierra Nevada. Paisaje, fauna, flora, itinerarios. Madrid, Edit. Rueda, 520 pp.

Navarro AlCALÁ-Zamora, P. (1979): Mecina. La cambiante estructura social de un pueblo de la Alpujarra, Madrid, Centro de Investigaciones Sociológicas, $371 \mathrm{pp}$.

NúÑez Noguerol, G. (1969): «La población y las formas de aprovechamiento de la Alpujarra oriental», Estudios Geográficos, XXX, pp. 241-305.

NÚÑEZ ROMERO-BALMAS, G. (1998): «La hidroelectricidad en pequeña escala», en TTTOS MARTínEz, M. (Coord.), Historia económica de Granada, Granada, Cámara de Comercio, Industria y Navegación, pp. 267-281.

NúNEz DE PRADo, M. (1753): Relación auténtica de la creación de la Renta de Población del reyno de Granada. Granada, Imprenta Real.

Orti Serrano, C. (1961): «Sierra Nevada y su riqueza minera», Bol. Cámara Comercio e Industria, 11, pp. 24-25.

Rodríguez García, M. (1965): La cabra montés en Sierra Nevada, Madrid, Ministerio de Agricultura, $95 \mathrm{pp}$.

RODRíGUEZ MARTÍNEZ, F. (1981): «Notas sobre la crisis y las posibilidades de desarrollo de la montaña mediterránea andaluza. El modelo de Sierra Nevada», Cuadernos Geográficos Universidad Granada, 11 (Monográfico sobre Sierra Nevada), pp. 267-281.

Rodríguez MARTínez, F. y ARIAS ABELLÁN, J. (1996): «Sierra Nevada entre la conservación y el desarrollo. Análisis y perspectivas de un Parque de alta montaña mediterránea, Boletín Real Sociedad Geográfica, CXXXII, pp. 243-275.

Rodríguez MARTínez, F. y JiméNEZ OlivenCIA, Y. (1995): «De la montaña al desierto. Algunas consecuencias del abandono agrícola en la periferia meridional de Sierra Nevada (España)», Paralelo $37^{\circ}$ (Almería), 16, pp. 85-94.

RODRÍGUEZ MARTínez, F. y JimÉnEZ OlIVENCIA, Y. (1996): «Abandono agrícola y desarrollo sostenible en Sierra Nevada», $1 .{ }^{a}$ Conferencia Internacional Sierra Nevada. Conservación y Desarrollo sostenible. Granada, Universidad, Junta de Andalucía, Unesco y Sierra Nevada, 1996, IV, pp. 477-491.

SÁnChez MARTínez, M. (1980): «Apogeo y crisis del estado cordobés», en Historia de Andalucía, Barcelona, Cupsa y Planeta, I, pp. 183-355.

SANTA CRUZ, J. J. (1993): La carretera de Sierra Nevada y otros escritos. Selección y estudio preliminar de M. Titos Martínez. Granada, Sierra Nevada 95, 351 pp.

SERMET, J. (1942): «Sierra Nevada», Estudios Geográficos, III, pp. 727-750.

(1951): «Les toits plats du Sud-Est de l'Espagne», Actes du Congrés Internationale de Géographie de Lisbonne, III, Lisbonne, pp. 141-154. (1953): L'Espagne du Sud. Grenoble-París, Arthaud, 396 pp.

Simonet, F. J. (1872): Descripción del reino de Granada sacada de los autores árabes. Granada.

Sole Sabaris, L. (1951): Los Pirineos. El medio y el hombre. Col. El Mundo y los Hombres, 8. Barcelona, Alberto Martín, $624 \mathrm{pp}$

Sole SABARIS, L. y Llopis LLADO, N. (1952): «Geografía física. El relieve», en TERÁN, M. DE, Geografía de España y Portugal, Barcelona, Montaner y Simón, I, pp. 416-468. 
SorRe, M. (1931): «Nomadisme agricole et transhumance dans la Sierra Nevada», Annales de Géographie, París, pp. 301-305.

Titos Martínez, M. (1996): Sierra Nevada: una gran historia. Monográfica Tierras del Sur, 17,2 vols. Granada, Universidad, Cetursa y Sogefinsa, 1108 pp.

Trillo SAN José, C. (1996): «La Alpujarra en la Edad Media: de una remota tierra de Al-Andalus a los señoríos castellanos», $1 .{ }^{a}$ Conferencia Internacional Sierra Nevada. Conservación y Desarrollo Sostenible, Granada, Universidad, Sierra Nevada 96, Junta de Andalucía, UNESCO, IV, pp. 29-49.

VeYret, P. (1972): Les Alpes. Col. Que sais-je?, n. ${ }^{\circ}$ 1463, París, PUF, 130 pp.

Villegas Molina, F. (1998): «El turismo», en Titos MarTínez, M. (Coord.), Historia económica de Granada, Granada, Cámara de Comercio, Industria y Navegación, pp. 283301.

Willkomm, M. (1993): Las Sierras de Granada. Estudio preliminar de J. Bosque Maurel. Col. Sierra Nevada y la Alpujarra, 8. Granada, Caja General de Ahorros y Sierra Nevada, $95,446 \mathrm{pp}$.

(1997): Granada y Sierra Nevada. Estudio preliminar de J. Molero Mesa. Col. Sierra Nevada y la Alpujarra, 22. Granada, Fundación Caja de Granada, 355 pp. 